\title{
Catalytic amine functionalization and polymerization of cyclic alkenes creates adhesive and self-healing materials
}

Damon J. Gilmour, ${ }^{\dagger}$ Tanja Tomkovic, ${ }^{\ddagger}$ Nirmalendu Kuanr, ${ }^{\dagger}$ Mitchell R. Perry, ${ }^{\dagger}$ Hans Gildenast, ${ }^{\dagger}$ Savvas G. Hatzikiriakos, ${ }^{*, \neq}$ and Laurel L. Schafer ${ }^{*, \dagger}$

\section{Supporting Information}

$\begin{array}{ll}\text { Experimental Details } & \text { S1 }\end{array}$

$\begin{array}{ll}\text { NMR Spectra } & \text { S9 }\end{array}$

$\begin{array}{ll}\text { GPC traces of polymers } & \text { S19 }\end{array}$

$\begin{array}{ll}\text { Thermal characterization plots } & \text { S25 }\end{array}$

$\begin{array}{ll}\text { Melt Rheology - Master curves } & \text { S27 }\end{array}$

$\begin{array}{ll}\text { Self-healing supplementary data } & \text { S27 }\end{array}$

$\begin{array}{ll}\text { PTFE adhesion raw data and images } & \text { S29 }\end{array}$

$\begin{array}{ll}\text { References } & \text { S31 }\end{array}$ 


\section{Experimental}

General Details: All reactions were performed under an inert atmosphere using a Schlenk double manifold equipped with $\mathrm{N}_{2}$ and high vacuum $\left(10^{-3} \mathrm{mbar}\right)$ or a glovebox filled with $\mathrm{N}_{2}$. All glassware used was heated above $160^{\circ} \mathrm{C}$ in an oven prior to use. Reactions were performed in threaded $20 \mathrm{~mL}$ scintillation vials equipped with a PTFE-coated magnetic stir bar and a PTFElined polypropylene screw-cap. Toluene and hexane were purified by passing over activated alumina columns prior to collection and storage in the glovebox. Thin layer chromatography (TLC) was performed on EMD Silica gel 60 F254 plates and visualized under a $254 \mathrm{~nm}$ UV light. Flash chromatography was performed using SilicaFlash F60 silica gel (230-400 mesh) (Silicycle) as a stationary phase and ACS grade Hexanes/Ethyl Acetate as a mobile phase.

Reagents: All reagents were purchased from commercial sources. 3-methyl 2-pyridone (Combiblocks) was purified by sublimation. Cyclooctadiene (Aldrich), N-methyl aniline (Aldrich), $N$ methyl cyclohexylamine (Oakwood) were stirred over $\mathrm{CaH}_{2}$ for a minimum of $2 \mathrm{~h}$, separated by distillation, then manipulated using standard Schlenk techniques. [ $\left.\mathrm{TaCl}_{2}\left(\mathrm{NMe}_{2}\right)_{3}\right]_{2}{ }^{1}$ and Chlorotris(dimethylamido) $\left(\kappa^{2}-N, O-3-\right.$ methyl-2-pyridonato)tantalum $(\mathrm{V})^{2}$ were prepared as per literature precedent. Grubbs Catalyst TM 2nd Generation (G2) (Sigma-Aldrich) was purchased and used without further purification. Grubbs Catalyst TM 3rd Generation (G3) was prepared as per literature precedent. ${ }^{3}$

NMR Spectroscopy: ${ }^{1} \mathrm{H}$ NMR spectra were collected using a Bruker Avance instrument operating at 300 or $400 \mathrm{MHz}$. Chemical shifts, $\delta$, are reported in parts per million (ppm) and coupling constants $\mathrm{J}$ are given in Hertz $(\mathrm{Hz})$. Abbreviations for NMR assignments are as follows: $\mathrm{s}=$ singlet; $\mathrm{d}=$ doublet; $\mathrm{dd}=$ doublet of doublets; $\mathrm{t}=$ triplet; $\mathrm{q}=$ quartet; $\mathrm{m}=$ multiplet; $\mathrm{br}=$ broad; appt $=$ apparent. ${ }^{13} \mathrm{C}$ and ${ }^{19} \mathrm{~F}$ NMR spectra were recorded on a Bruker Avance 300 instrument at $293 \mathrm{~K}$.

Gel Permeation Chromatography: Polymer $M_{n}, M_{w}$ and dispersity (Đ) were obtained using triple detection gel permeation chromatography (GPC). All the GPC characterizations were done in 
HPLC-grade THF at a flow rate of $1.0 \mathrm{~mL} / \mathrm{min}$ using a Malvern OMNISEC GPC instrument equipped with a Viscotek TGuard guard column (CLM3008), and Viscotek T3000 (CLM3003) and T6000 (CLM3006) GPC columns packed with porous poly(styrene-co-divinylbenzene) particles regulated at a room temperature. The instrument was equipped with triple detection to achieve the signal response from differential viscometer, differential refractive index and rightangle \& low-angle light scattering detectors. Calibration of inter detector distances was performed using a polystyrene standard from Malvern Inc. The RI increments $(d n / d c)$ were obtained by using $100 \%$ mass recovery methods from Malvern OMNISEC software with each polymer sample being run at least 3 times to ensure reproducibility.

Differential Scanning Calorimetry: Thermal properties of the samples were measured on a Netzsch DSC 214 Polyma differential scanning calorimeter. Analyses were performed in an inert atmosphere (nitrogen) with samples of approximately 5-10 $\mathrm{mg}$ in a stainless-steel pan. All analyses were conducted in duplicate. Samples were heated to $50{ }^{\circ} \mathrm{C}$ with a heating rate of $5{ }^{\circ} \mathrm{C} / \mathrm{min}$. They were held isothermally at $50{ }^{\circ} \mathrm{C}$ for $5 \mathrm{~min}$ in order to eliminate any thermal history followed by gradual cooling to $-50{ }^{\circ} \mathrm{C}$ with a cooling rate of $5{ }^{\circ} \mathrm{C} / \mathrm{min}$. The samples were then reheated to 50 ${ }^{\circ} \mathrm{C}$ with a heating rate of $5{ }^{\circ} \mathrm{C} / \mathrm{min}$. The glass transition temperatures were determined from the second heating ramp.

Thermogravimetric Analysis (TGA): Netzsch TG 209 F1 Libra $^{\circledR}$ thermogravimetric analyzer was used for the thermogravimetric experiments. All samples were primarily dried at $40{ }^{\circ} \mathrm{C}$ overnight. The tests of 4-10 mg of each sample were performed by continuously passing a high purity nitrogen stream $\left(99.5 \% \mathrm{~N}_{2}, 50 \mathrm{~cm}^{3} / \mathrm{min}\right)$ into the furnace at heating rate of $5{ }^{\circ} \mathrm{C} / \mathrm{min}$, from 25 to $600{ }^{\circ} \mathrm{C}$.

Sample preparation: Polymers were prepared as films for rheological testing. The precipitated polymer (0.5-1 g) was well dissolved in THF (ca. 10-20 mL) and solution cast in a custom fabricated PTFE mould. Solvent was allowed to evaporate at room temperature/ pressure overnight, followed by drying in a vacuum oven $\left(45^{\circ} \mathrm{C}\right)$. Films could then be carefully removed from the mould and used for analysis. During film-casting, polymers are noted to become darker in color, presumably due to oxidation of amine.

Rheological Measurements: Rheological characterization was conducted using the Anton Paar MCR 702 rotational rheometer, equipped with a cone-partitioned-plate geometry. The main 
advantage of this geometry is the elimination of the edge fracture. The top part of this type of geometry contains an $8 \mathrm{~mm}$ in diameter plate attached to the transducer (center plate), and a coaxial stationary ring (partitioned plate, $25 \mathrm{~mm}$ in diameter), which acts as a shield and prevents edge fracture of the sample. The bottom plate is $25 \mathrm{~mm}$ in diameter with an angle of $0.07 \mathrm{rad}$. The experiments were performed at distance gap of $51 \mu \mathrm{m}$.

The thermal stability of the samples was studied isothermally using dynamic time sweep test by applying the frequency of $0.1 \mathrm{~Hz}$ and shear strain of 0.01 for $2 \mathrm{hrs}$. An initial strain sweep test at the frequency of $0.1 \mathrm{~Hz}$ was used to detect the limits of the linear viscoelasticity. Frequency sweep experiments $(0.01-100 \mathrm{~Hz})$ at a fixed shear strain of 0.01 , which is within the linear viscoelastic region, were performed at different temperatures. Obtained experimental results are presented at the temperature of $30^{\circ} \mathrm{C}$.

Stress-strain measurements: The elongational viscoelastic properties were determined using the second generation Sentmanat Extensional Rheometer fuxture (SER2, Xpansion instruments) mounted on the Anton Paar MCR 501 rotational rheometer. The polymer specimens were prepared as described above and cut into strips with a specific width of $6 \mathrm{~mm}$. The tensile experiments were performed at room temperature by applying constant strain rate of 0.5 $\mathrm{mm} / \mathrm{min}$. Samples were elongated until breakage and the linear elongational strain was calculated by $\epsilon=\frac{L-L_{0}}{L_{0}} \times 100$, where $L_{0}$ is the initial length of the sample and $L$ is the length of the sample at time $t$. The Young's modulus was determined from the equation $\sigma=E \varepsilon$, $(\sigma$ is the tensile stress) which is valid only for the elastic response of the material. The tensile strength represents the maximum stress in the stress-strain curve and the ultimate elongation, $\varepsilon_{u}$, shows how much the material can elongate before fracture. The latter was calculated by using the following equation, $\varepsilon_{u}=\frac{L_{f}-L_{0}}{L_{0}} \times 100$, where $L_{f}$ is the final length of the sample before failure. 
Self-healing measurements: The self-healing ability of the functionalized polycyclooctenes was demonstrated by performing the following steps. Firstly, the stress-strain curve of the virgin sample was recorded at room temperature by applying a strain rate of $0.5 \mathrm{~mm} / \mathrm{min}$. Then the sample was cut into two pieces, and its parts were gently brought into contact without using any external stimuli, such as pressure, heat, or solvent. These were allowed to spontaneously heal as a single component for different healing times ( $5 \mathrm{~min}$ to $60 \mathrm{~min}$ ) at ambient conditions. Finally, the stressstrain curve was recorded by applying the same strain rate on the healed sample as in the case of the virgin sample. This cycle of stretching, breaking and healing was repeated numerous times.

Peel-strength measurements: Adhesion to PTFE was quantified using a Dynamic Mechanical analyzer (DMA, RSA G2 TA Instruments) equipped with tension fixture to perform peel strength measurements. A dilute solution of P1 was casted between two untreated PTFE sheets (homopolymer, Daikin America) and after drying the two sheets of PTFE were placed into contact with minimal pressure by hand. Test specimens were prepared in accordance with the DMA instrument specifications, $8 \mathrm{~mm}$ wide and $70 \mathrm{~mm}$ long. These were bonded over $50 \mathrm{~mm}$ of their total length to be able to clamp the unbonded peel arms onto the tension fixture. A constant peel rate of $10 \mathrm{~mm} / \mathrm{min}$ at room temperature was applied in axial mode. The testing was repeated ten times (Fig. S22, Table S1)

\section{Preparation of [Ta] Hydroaminoalkylation Catalyst}

Chlorotris(dimethylamido)( $\left.\kappa^{2}-\mathbf{N}, \mathbf{O}-3-m e t h y l-2-p y r i d o n a t o\right) t a n t a l u m(V) .{ }^{2}$ In $\quad$ a $\mathrm{N}_{2}$ filled glovebox, to a suspension of $\left[\mathrm{TaCl}_{2}\left(\mathrm{NMe}_{2}\right)_{3}\right]_{2}(0.23 \mathrm{~g}, 0.3 \mathrm{mmol})$ in toluene $(\sim 2 \mathrm{~mL})$ was added a suspension of sodium 3-methyl-2-pyridonate $(0.075 \mathrm{~g}, 0.6 \mathrm{mmol})$ in toluene $(\sim 2 \mathrm{~mL})$ at room temperature. Upon stirring overnight, the initially yellow, cloudy mixture became an orange, clear solution. Volatiles were removed en vacuo to give $0.25 \mathrm{~g}$ orange-brown oil $(90 \%)$. The crude residue was dissolved in $1.0 \mathrm{~g}$ toluene solvent $(0.25 \mathrm{w} / \mathrm{w} \%)$ and used for hydroaminoalkylation (HAA). ${ }^{1} \mathrm{H}$ NMR (400 MHz, $d 8$-tol): $\delta 8.23$ (d of d, $1 \mathrm{H}, \mathrm{ArH}$ ), $\delta 6.83$ (d, 1H, ArH), $\delta 6.20$ (t, $1 \mathrm{H}$, $\left.\mathrm{ArH}), \delta 3.75-3.53\left(\mathrm{br} \mathrm{s}, 18 \mathrm{H},\left(\mathrm{NCH}_{3}\right)_{2}\right)_{3}\right) \delta 2.10\left(\mathrm{~s}, 3 \mathrm{H}, \mathrm{CH}_{3}\right)$, as previously reported.

\section{General Monomer Synthesis}

Monomers for ROMP derived from cyclooctadiene were prepared by hydroaminoalkylation using the $[\mathrm{Ta}]$ catalyst. All reported yields are calculated post-column chromatography. 
M1. ${ }^{4}$ In a $\mathrm{N}_{2}$ filled glovebox, to a solution of [Ta] catalyst $(200 \mathrm{mg}, 5 \mathrm{~mol} \%)$ in toluene $(\sim 3 \mathrm{~mL})$ was added $N$-methyl aniline $(1 \mathrm{~g}, 9.34 \mathrm{mmol})$ followed by cyclooctadiene $(1.54 \mathrm{~g}, 14 \mathrm{mmol})$. The initially orange, cloudy solution was equipped with a stirring bar, capped, removed from the glovebox, and heated to $145{ }^{\circ} \mathrm{C}$ in an oil-bath. Upon reaching temperature the reaction mixture goes dark red and was then heated with stirring for $20 \mathrm{~h}$. After this time, the reaction was quenched with exposure to ambient atmosphere and the addition of $\sim 1 \mathrm{~mL}$ methanol. Purification was completed via automated column chromatography (0 to $20 \%$ gradient of ethyl acetate/hexanes) to afford 1.68g of pale-yellow oil (84.0\%).

${ }^{1} \mathbf{H}$ NMR (300 MHz, $\left.\mathrm{CDCl}_{3}\right): \delta 7.20\left(\mathrm{~d}\right.$ of d, $\left.{ }^{3} \mathrm{~J}_{\mathrm{AB}}=7.35 \mathrm{~Hz},{ }^{3} \mathrm{~J}_{\mathrm{AC}}=8.53 \mathrm{~Hz}, 2 \mathrm{H}, 2 \times \mathrm{ArH}\right), \delta 6.72$ $\left(\mathrm{t},{ }^{3} \mathrm{~J}_{\mathrm{AB}}=7.39 \mathrm{~Hz}, 1 \mathrm{H}, \operatorname{ArH}\right), \delta 6.64\left(\mathrm{~d},{ }^{3} \mathrm{~J}_{\mathrm{AC}}=8.79 \mathrm{~Hz}, 2 \mathrm{H}, 2 \mathrm{x} \operatorname{ArH}\right), \delta 5.68(\mathrm{~m}, 2 \mathrm{H}, 2 \mathrm{x}$ $\mathrm{RHC}=\mathrm{CHR}), \delta 4.09$ (br s, 1H, NH), $\delta 2.96\left(\mathrm{~m}, 2 \mathrm{H}, \mathrm{CH}_{2}\right), \delta 2.38(\mathrm{~m}, 1 \mathrm{H}, \mathrm{CH}), \delta 2.16(\mathrm{~m}, 3 \mathrm{H}$, $\left.\mathrm{CH}_{2}\right), \delta 1.81-1.19\left(\mathrm{~m}, 7 \mathrm{H}, \mathrm{CH}_{2}\right) \mathrm{ppm}$.

${ }^{13} \mathbf{C}\{1 \mathrm{H}\}$ NMR (75 MHz, $\left.\mathrm{CDCl}_{3}\right): \delta 148.7(\mathrm{C}), \delta 130.2(\mathrm{CH}), \delta 130.1(\mathrm{CH}), \delta 129.3(\mathrm{CH}), \delta 117.0$ $(\mathrm{CH}), \delta 112.7(\mathrm{CH}), \delta 51.7\left(\mathrm{CH}_{2}\right), \delta 37.8\left(\mathrm{CH}_{2}\right), \delta 33.5\left(\mathrm{CH}_{2}\right), \delta 31.2\left(\mathrm{CH}_{2}\right), \delta 28.3(\mathrm{CH}), \delta 26.0$ $(\mathrm{CH}), \delta 24.9(\mathrm{CH}) \mathrm{ppm}$.

HRMS-ESI (m/z) Calcd: 216.1752; found: 216.1748.

M2. In a $\mathrm{N}_{2}$ filled glovebox, to a solution of $\mathbf{1 . 9}(911 \mathrm{mg}, 5 \mathrm{~mol} \%)$ in toluene $(\sim 15 \mathrm{~mL})$ was added $N$-methylcyclohexylamine $(5.3 \mathrm{~g}, 47 \mathrm{mmol})$ followed by cyclooctadiene $(7.3 \mathrm{~g}, 66 \mathrm{mmol})$. The initially yellow, clear solution was equipped with a stirring bar, sealed with a cap, removed from the glovebox, and heated to $145^{\circ} \mathrm{C}$ in an oil-bath. Upon reaching temperature the reaction mixture slowly becomes orange and was then heated with stirring for $20 \mathrm{~h}$. After this time, the reaction was quenched with exposure to ambient atmosphere and the addition of $\sim 1 \mathrm{~mL}$ methanol. The solvent was removed under reduced pressure and the residue was applied to a plug of silica gel. Excess cyclooctadiene was washed away with hexanes and the product was subsequently eluted with a mixture of triethylamine and hexanes (1:14). The solvent was removed under reduced pressure and $8.3 \mathrm{~g}$ of product was obtained as a colourless oil $(80 \%)$.

${ }^{1} \mathbf{H}$ NMR $\left(300 \mathrm{MHz}, \mathrm{CDCl}_{3}\right): \delta 5.61(\mathrm{~m}, 2 \mathrm{H}, \mathrm{RHC}=\mathrm{CHR}), \delta 2.42\left(\mathrm{~m}, 2 \mathrm{H}, \mathrm{CH}_{2}\right), \delta 2.34(\mathrm{~m}, 1 \mathrm{H}$, $\mathrm{CH}), \delta 2.12\left(\mathrm{~m}, 4 \mathrm{H}, \mathrm{CH}_{2}\right), \delta 1.88-1.00(17 \mathrm{H}) \mathrm{ppm}$. 
${ }^{13} \mathbf{C}\{\mathbf{1 H}\}$ NMR (75 MHz, CDCl 3$): \delta 130.2(\mathrm{CH}), \delta 129.9(\mathrm{CH}), \delta 56.9(\mathrm{CH}), \delta 54.9\left(\mathrm{CH}_{2}\right), \delta 38.1$ $(\mathrm{CH}), \delta 33.7\left(\mathrm{CH}_{2}\right), \delta 33.6\left(\mathrm{CH}_{2}\right), \delta 31.6(\mathrm{CH} 2), \delta 28.2(\mathrm{CH}), \delta 26.2\left(\mathrm{CH}_{2}\right), \delta 25.9\left(\mathrm{CH}_{2}\right), \delta 25.1$ $\left(\mathrm{CH}_{2}\right), \delta 24.9\left(\mathrm{CH}_{2}\right) \mathrm{ppm}$.

HRMS-ESI (m/z) Calcd: 222.2222; found: 222.2228.

M3. Synthesis of tertiary amine-containing monomer M3 was carried out from sec. aminecontaining monomer M1 by using Methyl iodide as the methylating agent. To an ice-cold stirring solution of M1 (1.0 g, 1 eq., $4.645 \mathrm{mmol})$ in dimethylformamide (DMF) $(20 \mathrm{~mL})$ was added potassium carbonate $(1.926 \mathrm{~g}, 3$ eq., $13.93 \mathrm{mmol})$ followed by an ice-cold solution of methyl iodide $(0.9 \mathrm{~mL}, 3$ eq., $14.46 \mathrm{mmol}$ ) in $5 \mathrm{~mL} \mathrm{DMF}$ at $0{ }^{\circ} \mathrm{C}$ and the resultant mixture was stirred for $12 \mathrm{~h}$ at RT. The progress of the reaction was monitored by TLC. The reaction mixture was diluted with ethylacetate $(50 \mathrm{~mL})$, washed with water $(3 \times 50 \mathrm{~mL})$. The organic layer was washed with brine $(3 \times 50 \mathrm{~mL})$ and dried over anhydrous $\mathrm{Na}_{2} \mathrm{SO}_{4}$. The organic layer was concentrated, and the desired product obtained as a pale-yellow oil ( $0.88 \mathrm{~g}, 83 \%)$ after purification by flash-column chromatography (hexane/EtOAc $=95 / 5 v / v)$.

${ }^{1} \mathbf{H}$ NMR (400 MHz, $\left.\mathrm{CDCl}_{3}, 298 \mathrm{~K}\right): \delta 7.26(\mathrm{dd}, J=8.6,7.2 \mathrm{~Hz}, 2 \mathrm{H}), 6.74-6.72(\mathrm{~m}, 3 \mathrm{H}), 5.69$ (m, 2H), 3.17 (dd, $J=14.3,7.4 \mathrm{~Hz}, 1 \mathrm{H}), 3.07$ (dd, $J=14.3,8.3 \mathrm{~Hz}, 1 \mathrm{H}), 2.96$ (s, 3H), 2.38 (m, 1H), $2.24(\mathrm{~m}, 1 \mathrm{H}), 2.15(\mathrm{~m}, 2 \mathrm{H}), 1.90(\mathrm{br} \mathrm{m}, 1 \mathrm{H}), 1.72-1.70(\mathrm{~m}, 2 \mathrm{H}), 1.56(\mathrm{~m}, 1 \mathrm{H}), 1.53-1.42$ (m, 2H), $1.19-1.16(\mathrm{~m}, 1 \mathrm{H}) \mathrm{ppm}$.

${ }^{13} \mathbf{C}\left\{{ }^{1} \mathbf{H}\right\}$ NMR $\left(100 \mathrm{MHz}, \mathrm{CDCl}_{3}, 298 \mathrm{~K}\right): \delta 150.05(\mathrm{C}), 130.31(\mathrm{CH}), 129.96(\mathrm{CH}), 129.09(\mathrm{CH})$, $115.76(\mathrm{CH}), 111.98(\mathrm{CH}), 60.30\left(\mathrm{CH}_{3}\right), 38.94\left(\mathrm{CH}_{2}\right), 36.86\left(\mathrm{CH}_{2}\right), 33.15(\mathrm{CH}), 30.25\left(\mathrm{CH}_{2}\right)$, $28.07\left(\mathrm{CH}_{2}\right), 25.82\left(\mathrm{CH}_{2}\right), 25.06\left(\mathrm{CH}_{2}\right) \mathrm{ppm}$.

HRMS-ESI (m/z) Calcd: 229.1830; found: 229.1834.

\section{General Polymer Synthesis}

Polymerization of monomers M1 and M3 was completed using ring-opening metathesis polymerization (ROMP) using Grubbs Catalyst ${ }^{\mathrm{TM}}$ 2nd Generation. In a $\mathrm{N}_{2}$ filled glovebox, to a stirring solution containing $1 \mathrm{~g}$ monomer in $\mathrm{CH}_{2} \mathrm{Cl}_{2}$ was added a solution of catalyst $([\mathrm{M}] /[\mathrm{I}]=$ 100) in $\mathrm{CH}_{2} \mathrm{Cl}_{2}$. Reactions were allowed to proceed for minimum $1 \mathrm{hr}$ to ensure full conversion, upon completion of the reaction the solution slowly goes light amber-yellow/green from the originally dark amber solution. Reactions were quenched via exposure to ambient atmosphere and drop-wise addition of an excess of ethyl vinyl ether ( $\min$. of 2 drops per $\mathrm{mg}$ of [Ru] catalyst) and 
left to stir for a minimum of thirty minutes, after which the solution slowly changes color to dark amber/black. The polymer was precipitated as a gum-like off-white solid via drop-wise addition to a stirring vortex of methanol $\left(-35^{\circ} \mathrm{C}\right.$, minimum of $1 \mathrm{~mL}$ per $\mathrm{mg}$ polymer). Isolation was completed by decanting the supernatant and overnight drying of the collected material under high vacuum. All characterization was thereafter completed with the exception of GPC analysis, for which further purification was completed via two additional precipitations (using addition of a $\mathrm{CH}_{2} \mathrm{Cl}_{2}$ solution of the polymer into a large excess of methanol) followed by drying in a vacuum oven.

P1. Prepared as above to afford $0.840 \mathrm{~g}$ of an off-white gum-like solid (84\%). ${ }^{1} \mathbf{H}$ NMR (300 MHz, $\left.\mathrm{CDCl}_{3}\right): \delta 7.17(\mathrm{~m}, 2 \mathrm{H}, 2 \times \mathrm{ArH}), \delta 6.73(\mathrm{br} \mathrm{s}, 3 \mathrm{H}, 3 \times \mathrm{ArH}), \delta 5.40$ (m, 2H, $\left.2 \times \mathrm{RHC}=\mathrm{CHR}\right), \delta$ $3.03\left(\mathrm{~d}, 2 \mathrm{H}, \mathrm{CH}_{2}\right), \delta 2.00\left(\mathrm{~m}, 4 \mathrm{H}, \mathrm{CH}_{2}\right), \delta 1.68$ (br s, 1H, CH), $\delta 1.49-1.26\left(\mathrm{~m}, 6 \mathrm{H}, \mathrm{CH}_{2}\right) \mathrm{ppm}$.

P2. In a $\mathrm{N}_{2}$ filled glovebox, $\mathbf{M} 2(1 \mathrm{~g})$ and Grubbs $3^{\text {rd }}$ generation catalyst $(\mathbf{G 3})([\mathrm{M}] /[\mathrm{I}]=100)$ were combined in toluene in a PTFE-sealed reaction vessel. The reaction was then heated to $90{ }^{\circ} \mathrm{C}$ in an oil-bath for $24 \mathrm{~h}$. The solution became brown and the reaction was quenched with ethyl vinyl ether and stirred for another 30 min before the a majority of solvent was reduced under vacuum. The concentrated residue was precipitated in cold $\mathrm{MeOH}$ to afford $800 \mathrm{mg}$ of an off-white solid $(80 \%)$. After isolation, the sample is insoluble in common solvents once completely dried. Characterization by NMR spectroscopy was conducted with a partially dried sample after precipitation. ${ }^{1} \mathbf{H}$ NMR (300 MHz, $\mathrm{CDCl}_{3}$ ): $\delta 5.53$ (br s, $2 \mathrm{H}, \mathrm{RHC}=\mathrm{CHR}$ ), $\delta 2.53$ (br s, 2H, $\mathrm{CH}_{2}$ ), $\delta 2.37$ (m, 1H, CH), $\delta 2.11$ (br s, 4H, $\left.\mathrm{CH}_{2}\right), \delta 1.99-1.05$ (m, 17H, CH, $\left.\mathrm{CH}_{2}\right) \mathrm{ppm}$.

P3. Prepared as above to afford $0.860 \mathrm{~g}$ of sticky, dark coloured solid (86\%). ${ }^{1} \mathrm{H} \mathrm{NMR} \mathrm{(400} \mathrm{MHz,}$ $\left.\mathrm{CDCl}_{3}\right) \delta 7.28-7.26(\mathrm{~m} \mathrm{2H}), 6.72(\mathrm{~d}, J=7.2 \mathrm{~Hz}, 3 \mathrm{H}), 5.42$ (br s, 2H), 3.19 (br s, 2H), 2.96 (br s, $3 \mathrm{H}), 2.05-2.00$ (br m, 4H), 1.88 (br s, 1H), 1.40 (br s, 6H) ppm.

\section{Polymer Hydrogenation}

P1H was synthesized as per literature procedure. ${ }^{5-6}$ To a $100 \mathrm{~mL}$ reaction vessel, equipped with a PTFE-coated stir bar and a PTFE capped-valve and side-arm, was added P1 (480 mg, 2 mmol alkene) and $p$-toluenesulfonyl hydrazide $(1.5 \mathrm{~g}, 8 \mathrm{mmol})$ in xylene $(15 \mathrm{~mL})$. Approximately $3 \mathrm{mgs}$ of 2,4,6-tri-tert-butyl phenol added as a radical trap. The resulting heterogeneous mixture was degassed using three freeze-pump-thaw cycles under an $\mathrm{N}_{2}$ atmosphere. The vessel was refilled 
with $\mathrm{N}_{2}$, sealed and heated to $130{ }^{\circ} \mathrm{C}$ in an oil-bath for a minimum of 8 hours. After the reaction, a pale-yellow, clear solution was obtained. The vessel was opened and the mixture transferred to a separatory funnel, using ethyl acetate $(50 \mathrm{~mL})$ to quantitatively transfer. The organic layer was washed three times with $3 \mathrm{M} \mathrm{NaOH}$, then once with brine, then reduced to $\sim 3 \mathrm{~mL}$ via rotary evaporation under reduced pressure. This residue was then added drop-wise to a large excess of stirring methanol $\left(-35^{\circ} \mathrm{C}, 250 \mathrm{~mL}\right)$ to afford the product as an off-white, gummy solid. After three successive precipitations, $0.350 \mathrm{~g}$ of material was obtained (73.0 \%). ${ }^{1} \mathbf{H} \mathbf{~ N M R}\left(300 \mathrm{MHz}, \mathrm{CDCl}_{3}\right)$ : $\delta 7.17(\mathrm{~m}, 2 \mathrm{H}, 2 \times \operatorname{ArH}), \delta 6.69(\mathrm{t}, 1 \mathrm{H}, \operatorname{ArH}), \delta 6.63(\mathrm{~d}, 2 \mathrm{H}, \operatorname{ArH}), \delta 3.01(\mathrm{~d}, 2 \mathrm{H}, \mathrm{CH} 2), \delta 1.61(\mathrm{br}$ $\mathrm{s}, 1 \mathrm{H}, \mathrm{CH}), \delta 1.28\left(\mathrm{~m}, 14 \mathrm{H}, \mathrm{CH}_{2}\right) \mathrm{ppm}$. 


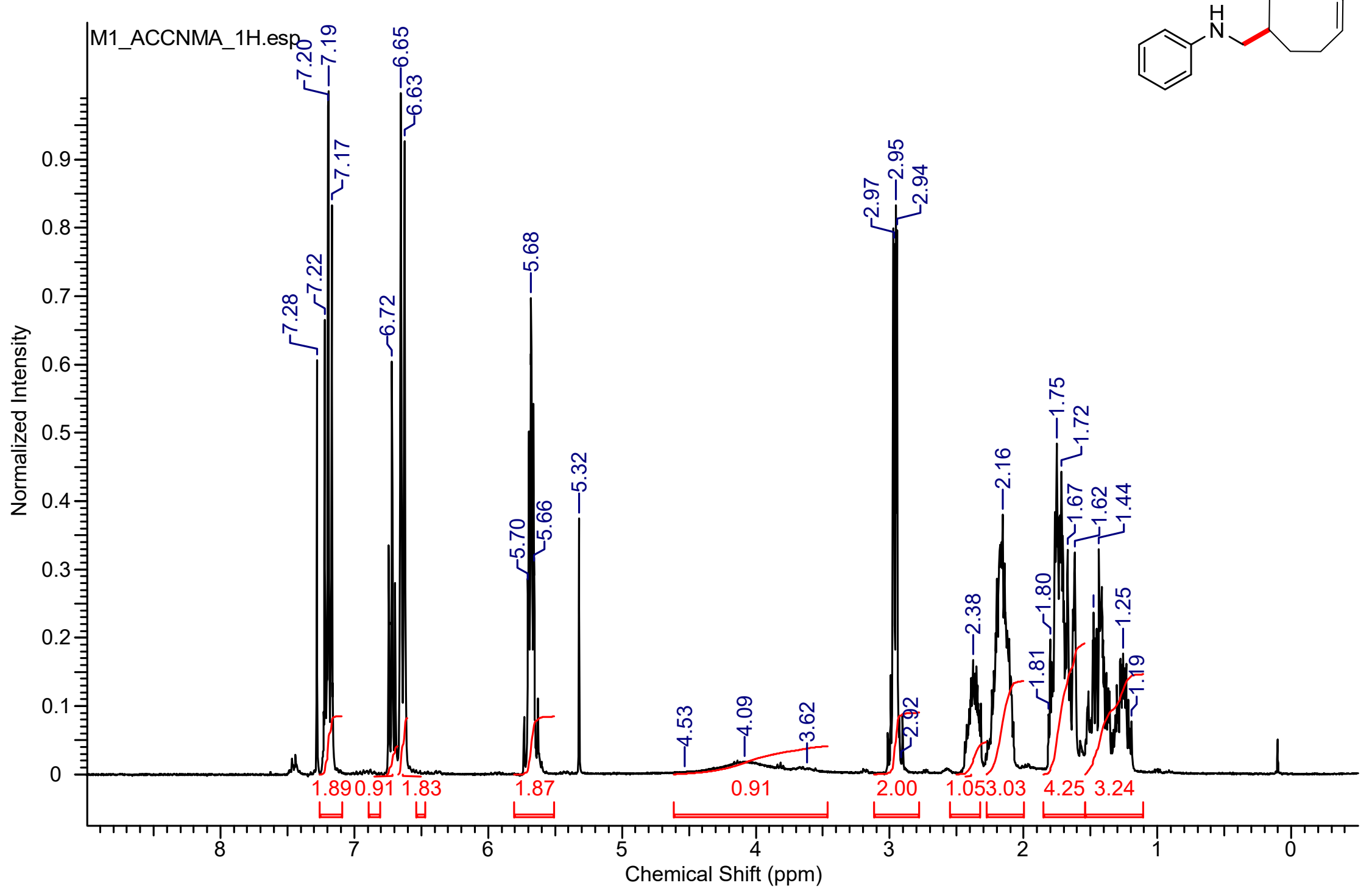

Figure S 1: ${ }^{1} \mathrm{H}$ NMR spectrum $\left(300 \mathrm{MHz}, \mathrm{CDCl}_{3}, 298 \mathrm{~K}\right)$ of M1 


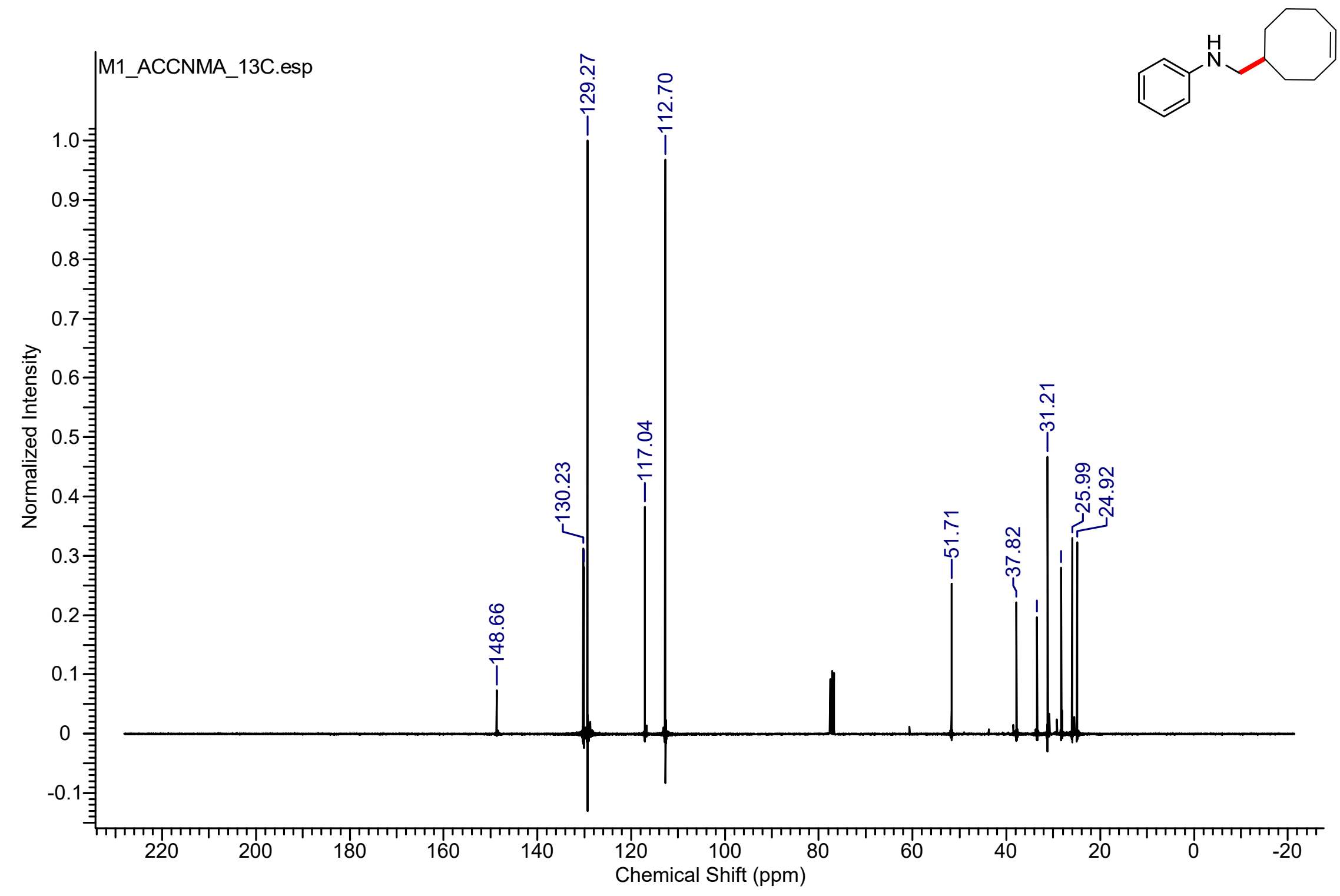

Figure S 2: ${ }^{13} \mathrm{C}$ NMR Spectrum $\left(\mathrm{CDCl}_{3}, 75 \mathrm{MHz}, 293 \mathrm{~K}\right)$ of M1 


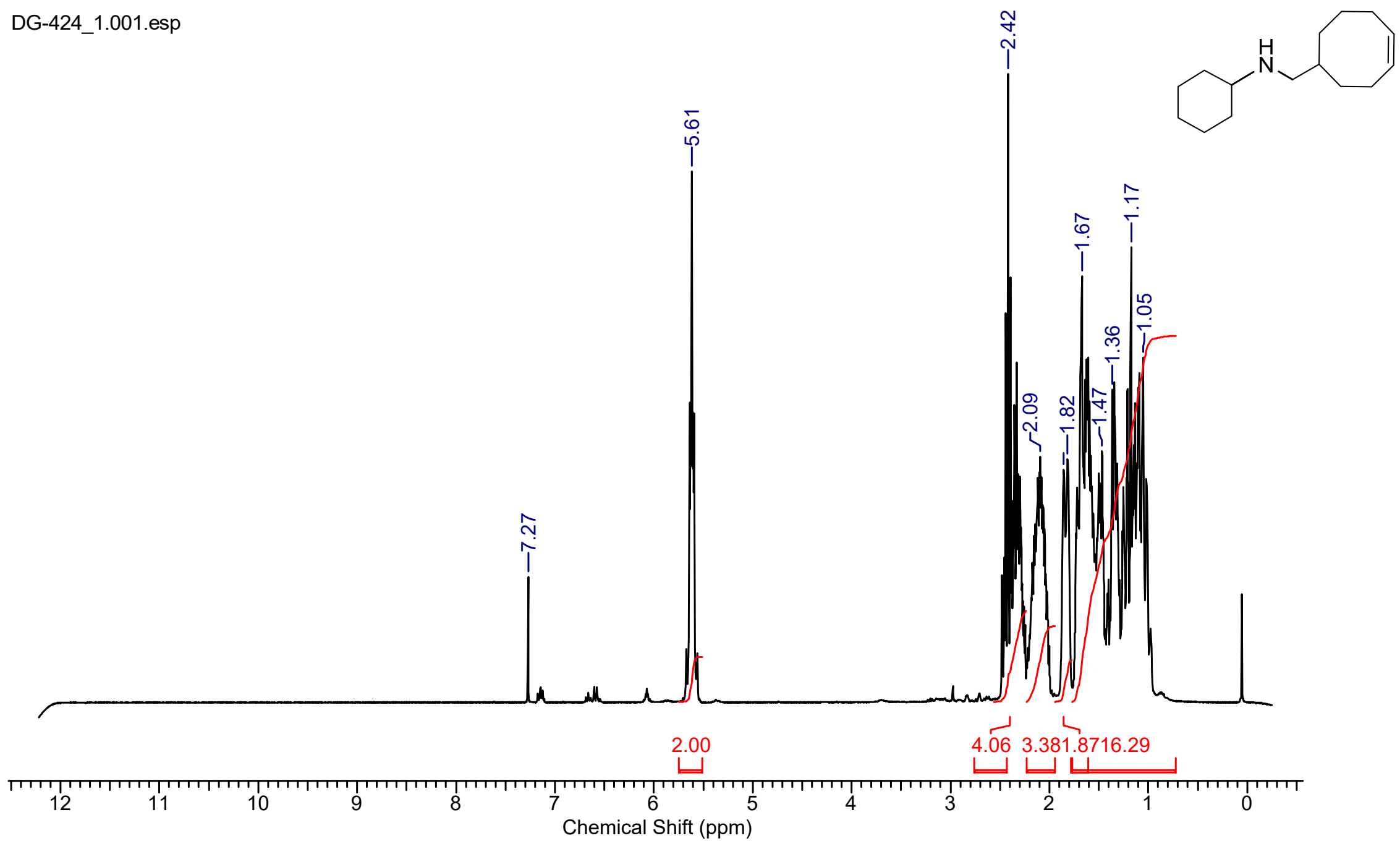

Figure S 3: ${ }^{1} \mathrm{H}$ NMR spectrum $\left(300 \mathrm{MHz}, \mathrm{CDCl}_{3}, 298 \mathrm{~K}\right.$ ) of $\mathbf{M 2}$ 


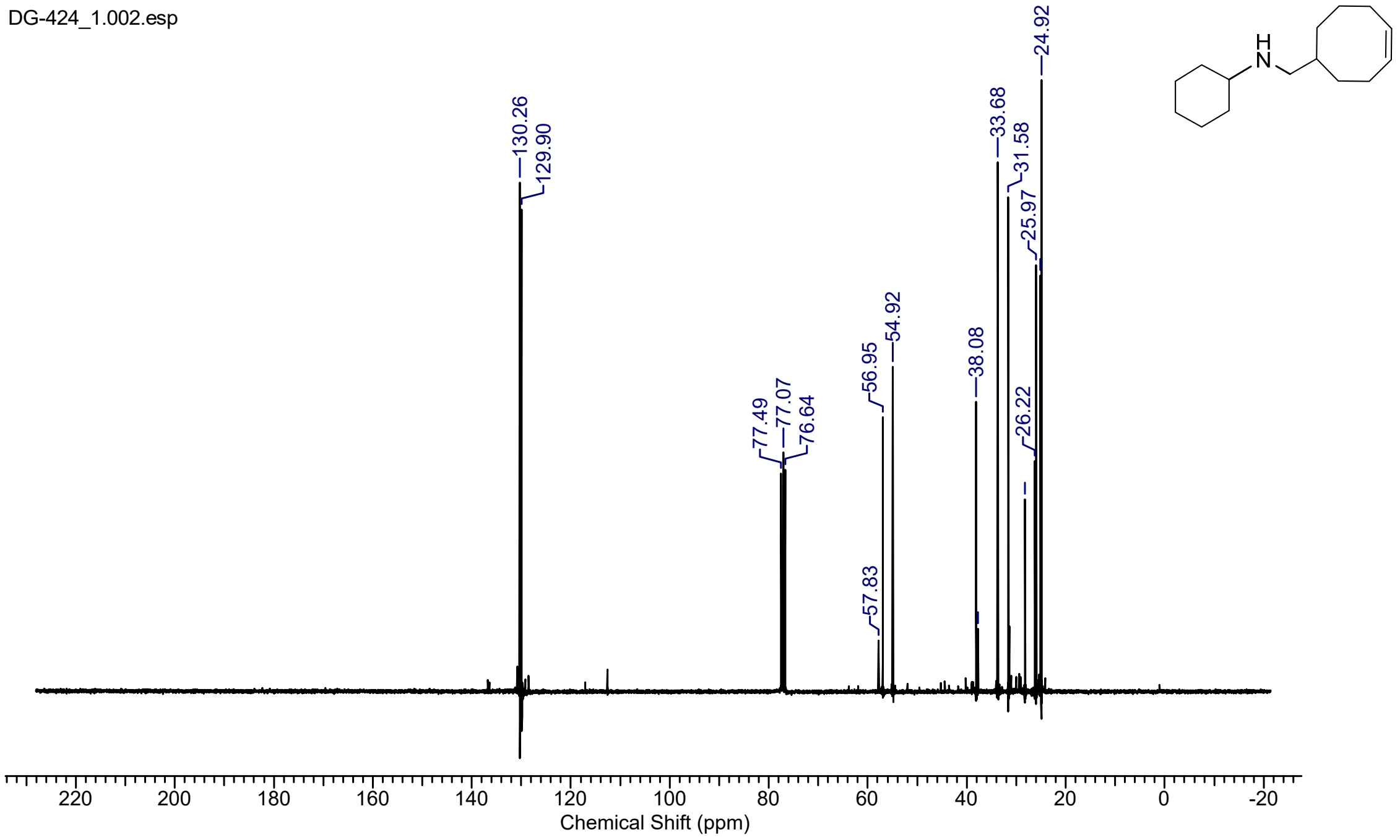

Figure S 4: ${ }^{13} \mathrm{C}$ NMR spectrum $\left(75 \mathrm{MHz}, \mathrm{CDCl}_{3}, 298 \mathrm{~K}\right)$ of $\mathbf{M 2}$ 


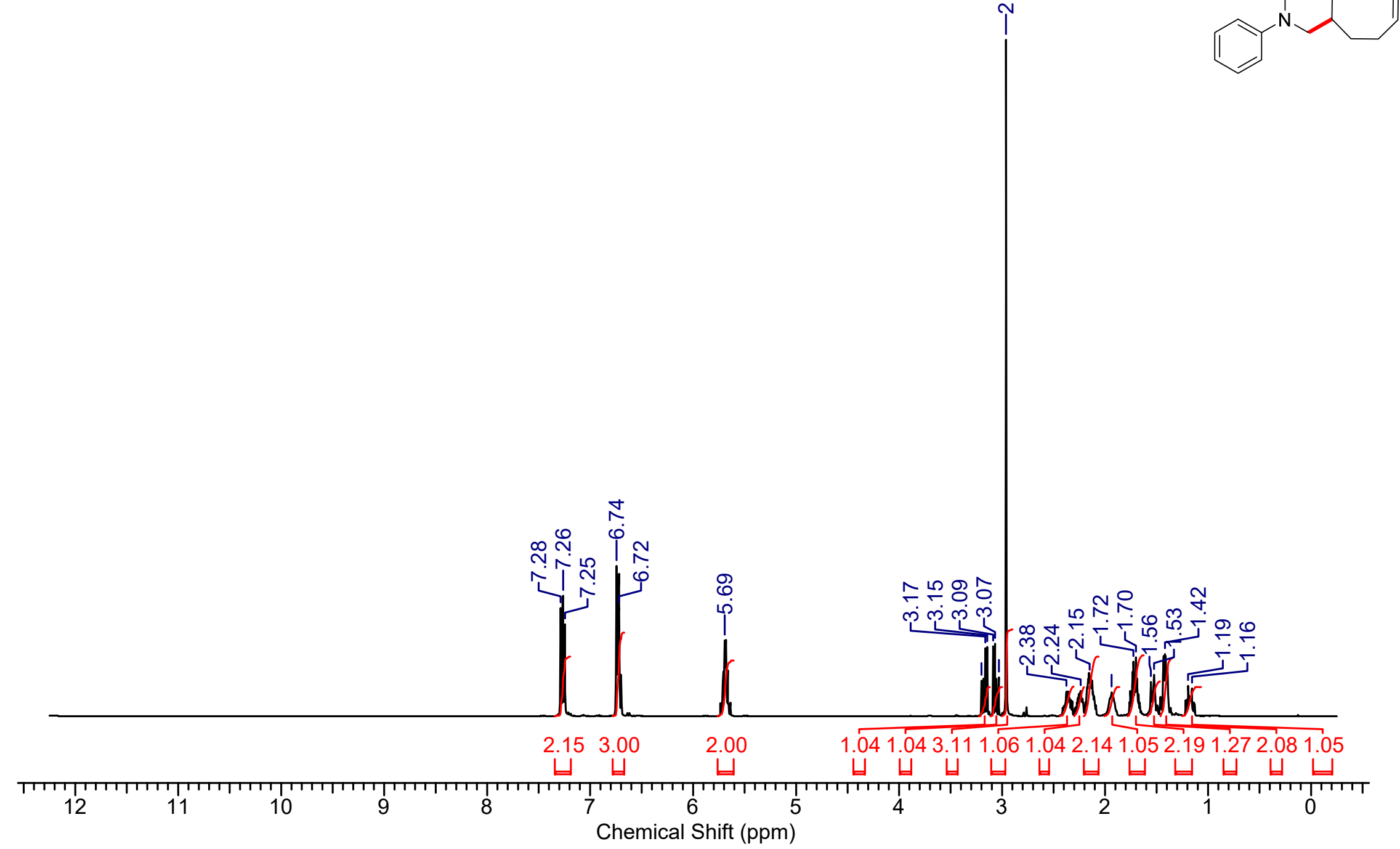

Figure S 5: ${ }^{1} \mathrm{H}$ NMR spectrum (400 MHz, $\mathrm{CDCl}_{3}, 298 \mathrm{~K}$ ) of $\mathbf{M 3}$ 


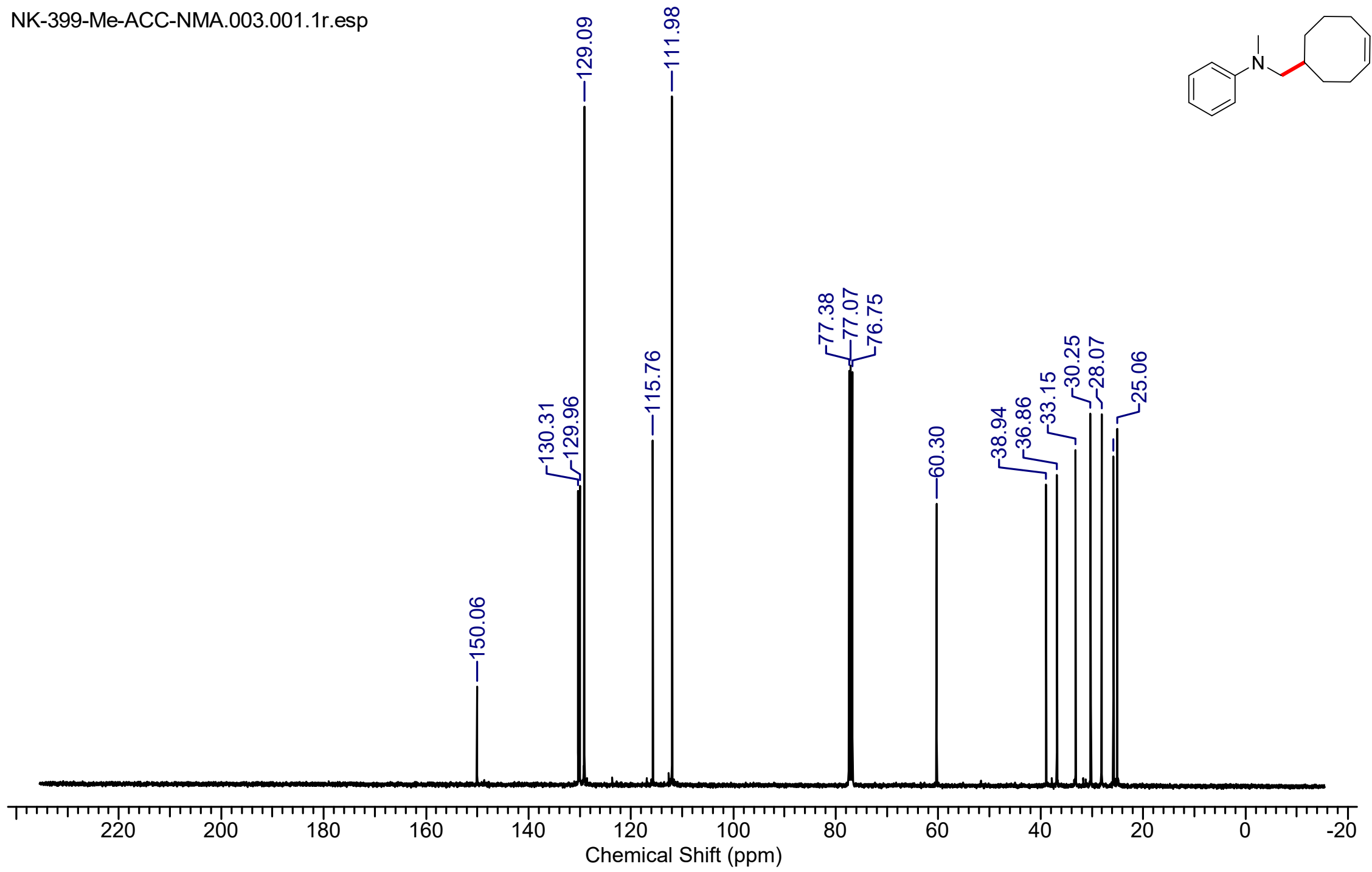

Figure S 6: ${ }^{13} \mathrm{C}$ NMR Spectrum $\left(\mathrm{CDCl}_{3}, 75 \mathrm{MHz}, 293 \mathrm{~K}\right)$ of $\mathbf{M 3}$ 


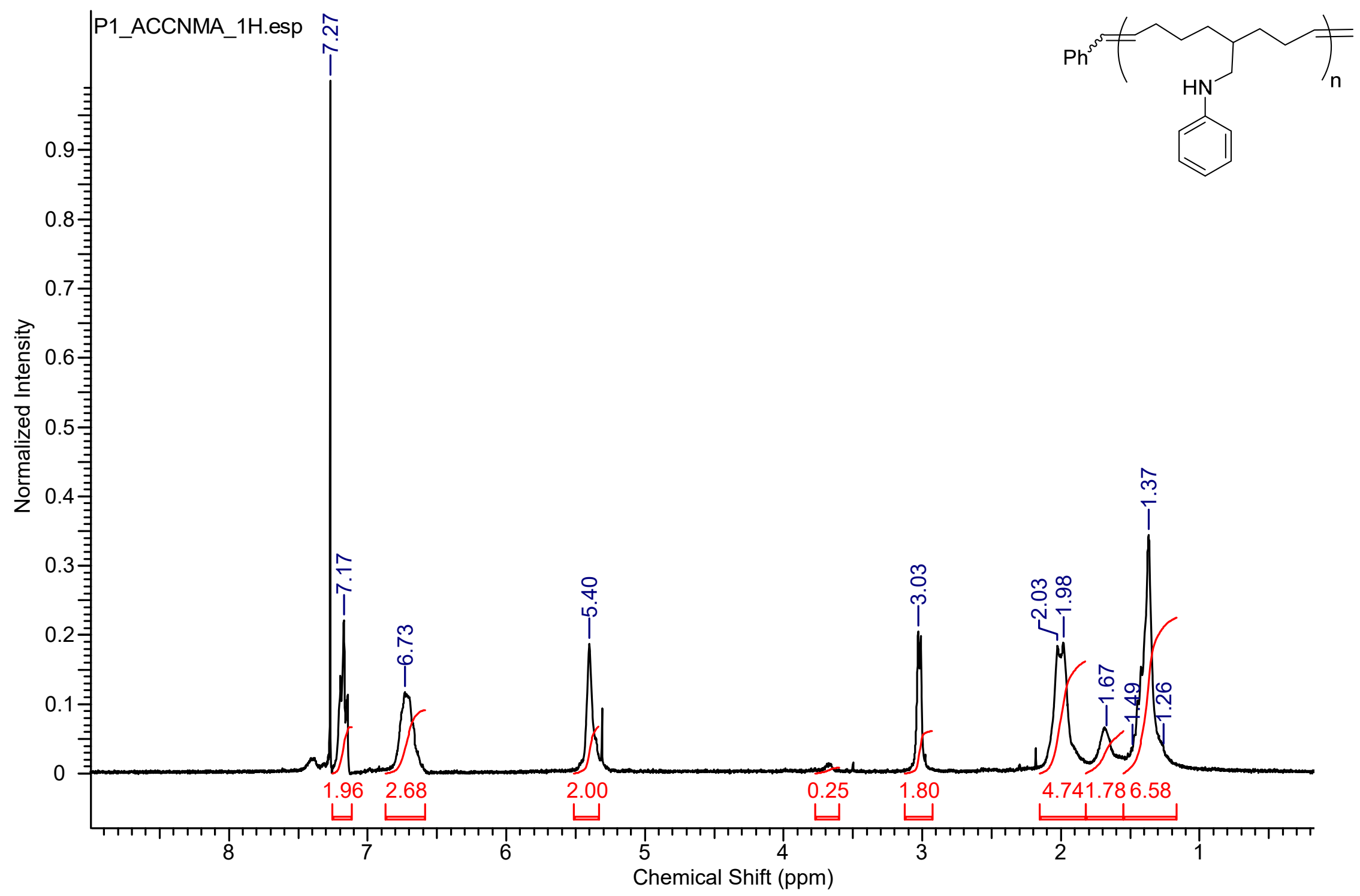

Figure S 7: ${ }^{1} \mathrm{H}$ NMR spectrum (300 MHz, $\mathrm{CDCl}_{3}, 298 \mathrm{~K}$ ) of $\mathbf{P 1}$ 


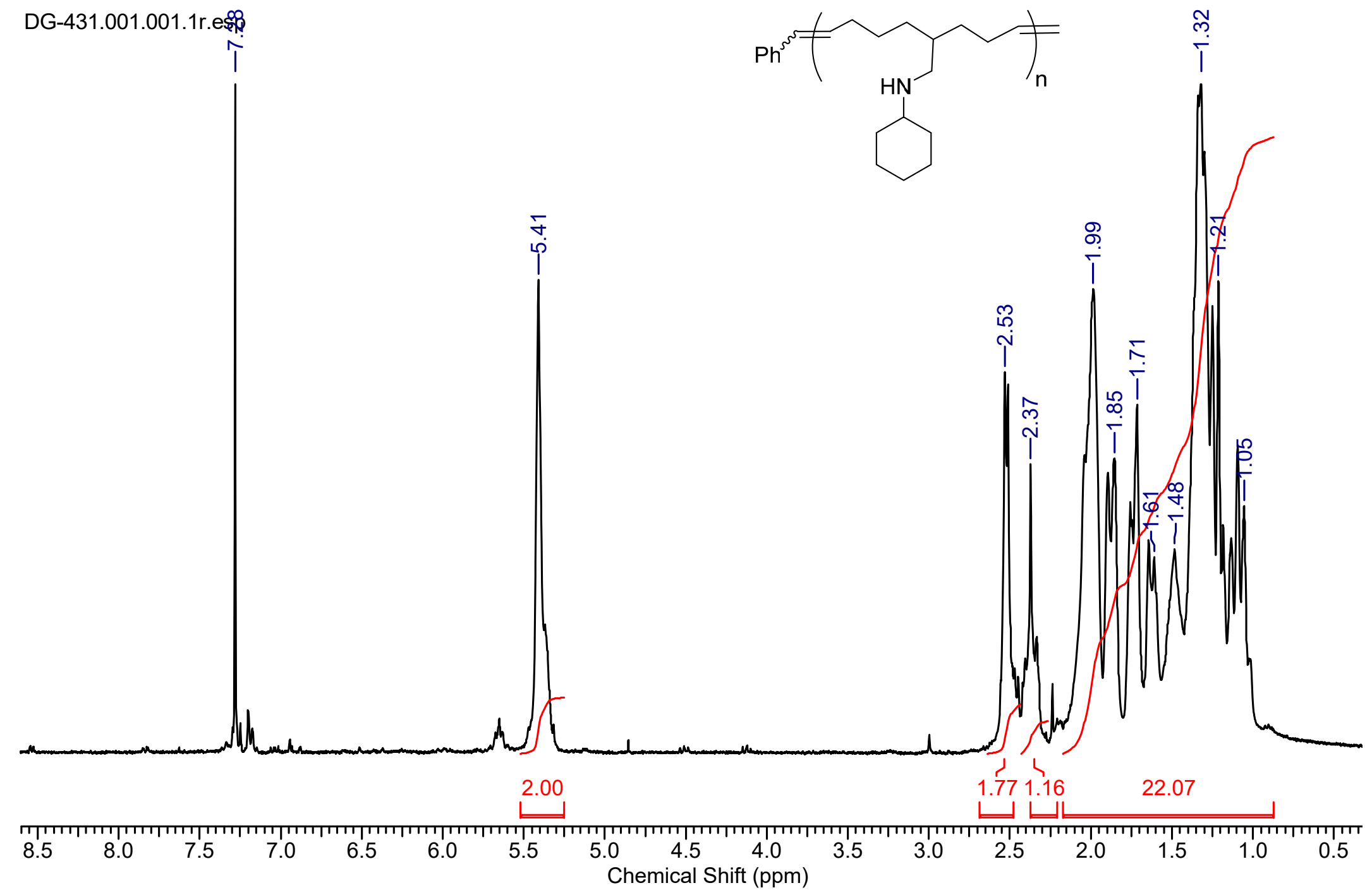

Figure S 8: ${ }^{1} \mathrm{H}$ NMR spectrum (300 MHz, $\mathrm{CDCl}_{3}, 298 \mathrm{~K}$ ) of $\mathbf{P 2}$ 


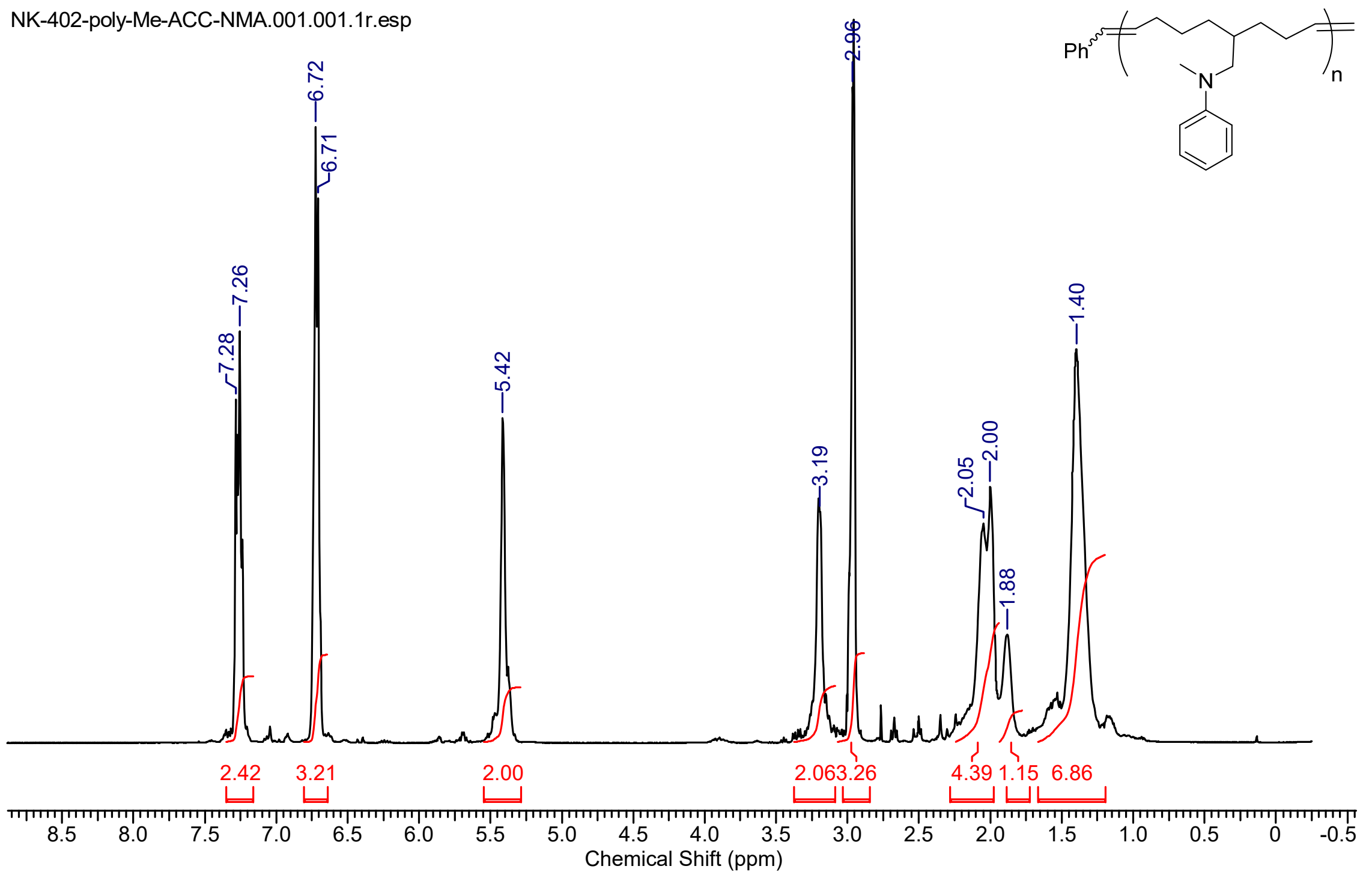

Figure S 9: ${ }^{1} \mathrm{H}$ NMR spectrum $\left(300 \mathrm{MHz}, \mathrm{CDCl}_{3}, 298 \mathrm{~K}\right)$ of $\mathbf{P 3}$ 


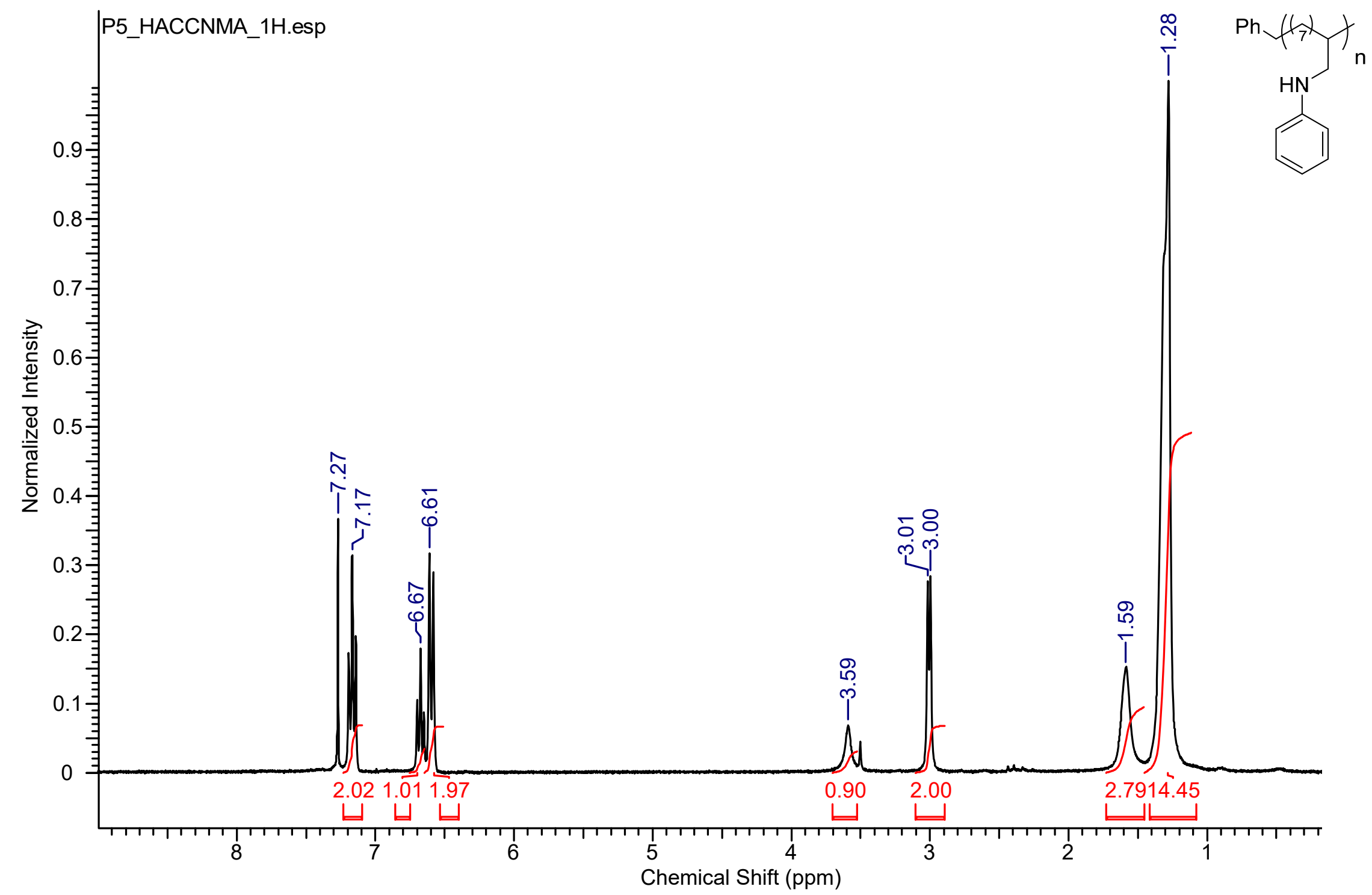

Figure S 10: ${ }^{1} \mathrm{H}$ NMR spectrum (300 MHz, $\mathrm{CDCl}_{3}, 298 \mathrm{~K}$ ) of $\mathbf{P 1 H}$ 


\section{Gel Permeation Chromatography (GPC) chromatograms of the polymers:}

All the GPC characterizations were done in HPLC-grade THF at a flow rate of $1.0 \mathrm{~mL} / \mathrm{min}$ using a Malvern OMNISEC GPC instrument equipped with a Viscotek TGuard guard column (CLM3008), and Viscotek T3000 (CLM3003) and T6000 (CLM3006) GPC columns packed with porous poly(styrene-co-divinylbenzene) particles regulated at a room temperature. The instrument was equipped with triple detection to achieve the signal response from differential viscometer, differential refractive index and right-angle \& low-angle light scattering detectors. Calibration of inter detector distances was performed using a polystyrene standard from Malvern Inc in order to determine the Detector Response Constants.

The absolute molecular weights are obtained by combining the response from the RI and LS detectors. The baseline corrections of the chromatograms are followed by selection of the overlapping regions of the RI, viscometer and LS detectors. The predefined MALVERN method (Calculate $d n / d c$ from the sample concentration) is applied to the area selected in the RI detector in order to determine the RI increments $(d n / d c)$ by using $100 \%$ mass recovery methods by taking into account the sample concentration. This is further used for obtaining the absolute molecular weights from the responses received from the LS detectors. Since the software calculates the molecular weight from the RI and LS signals, absence of LS signals after the major eluting peaks won't contribute to the molecular weight calculation.

A demonstration of molecular weight determination of $\mathbf{P 1}$ is shown in the following example. Similarly, molecular weights of rest of the polymers were determined. 


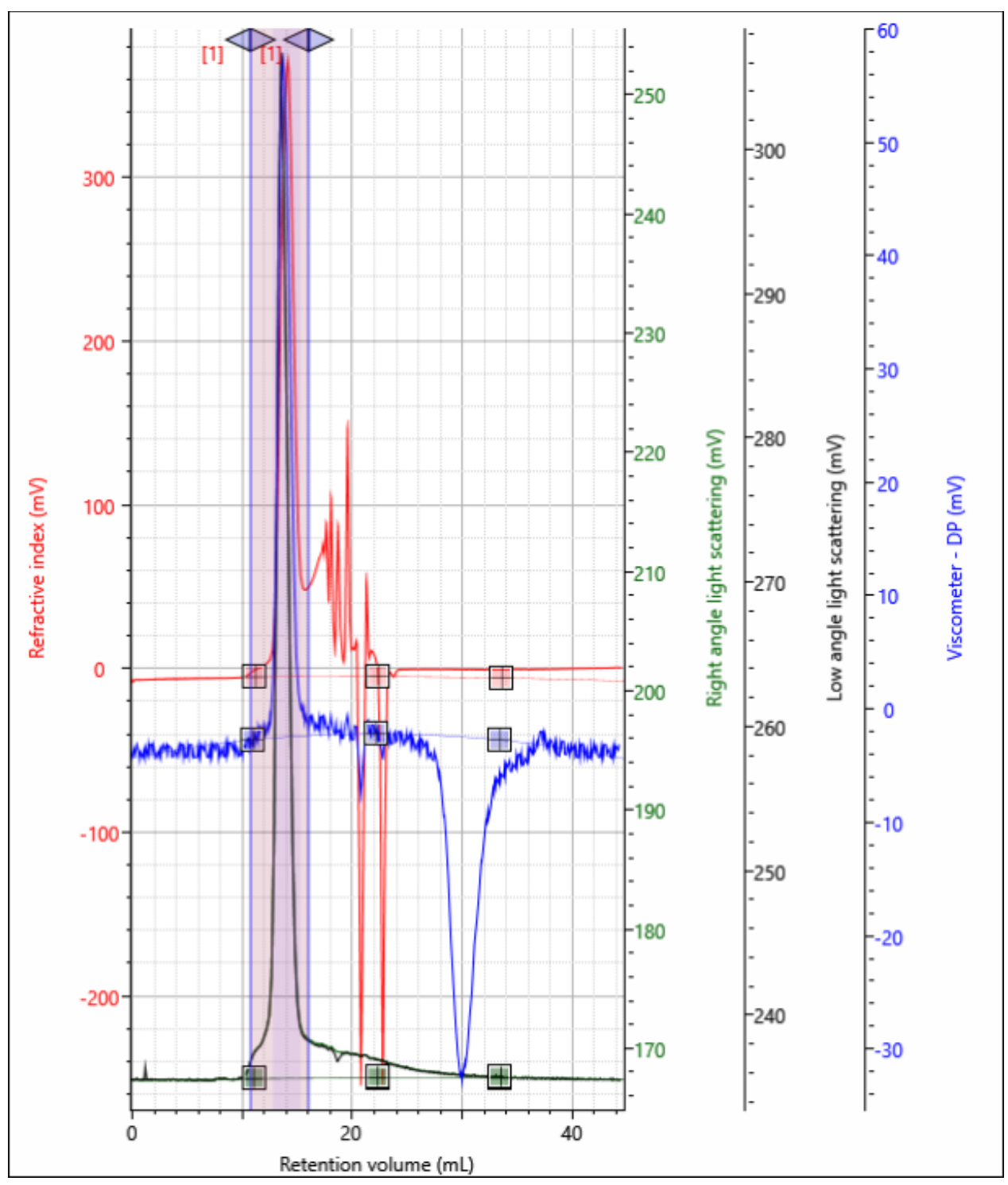

Figure S 11: RI, viscometer, LALS and RALS responses obtained from the software for polymer P1. The selected region shows the area selected for applying the method to determine $d n / d c$ of the sample. 


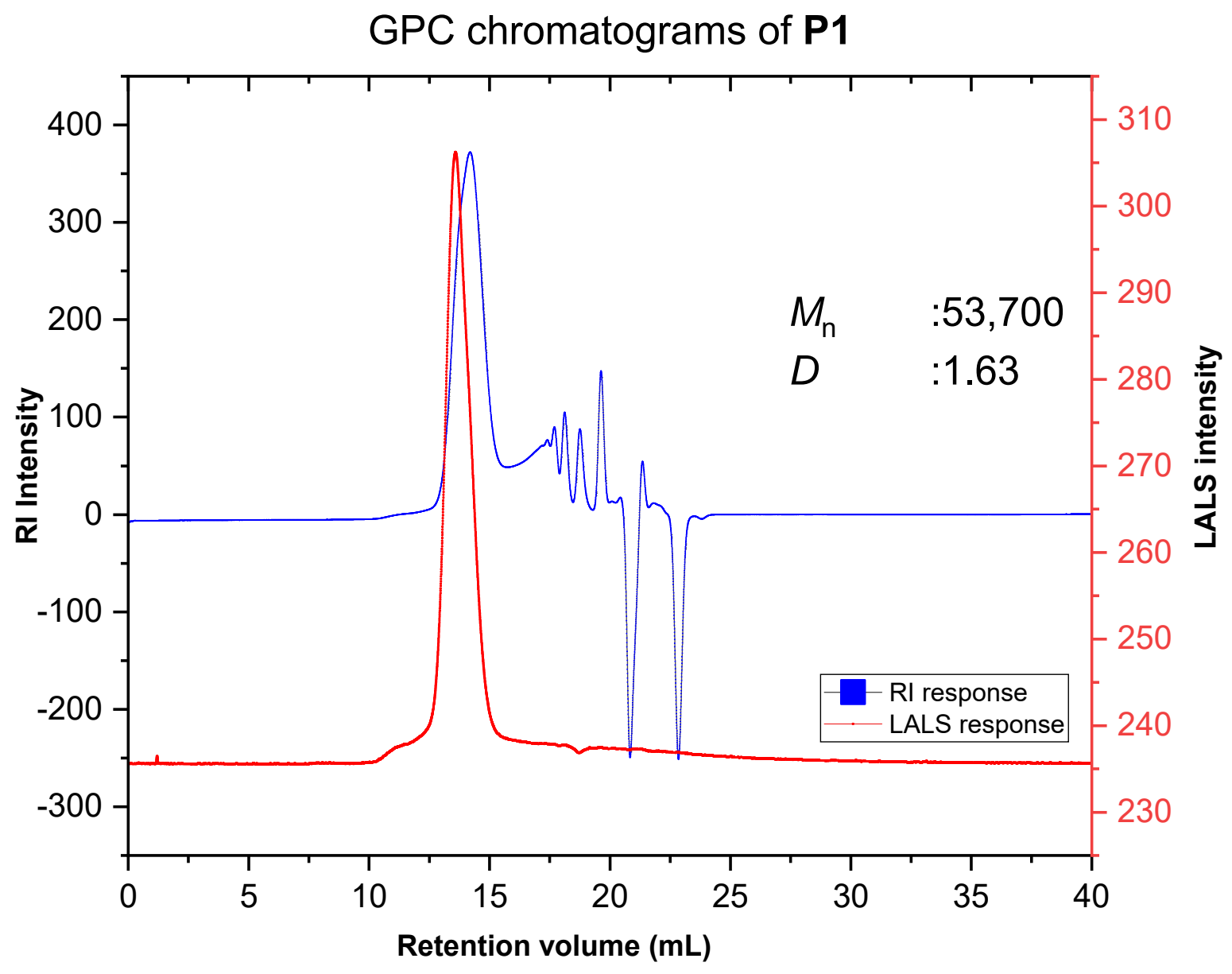

Figure S 12: RI and LALS response of the above polymer P1 


\section{GPC chromatograms of P1H}

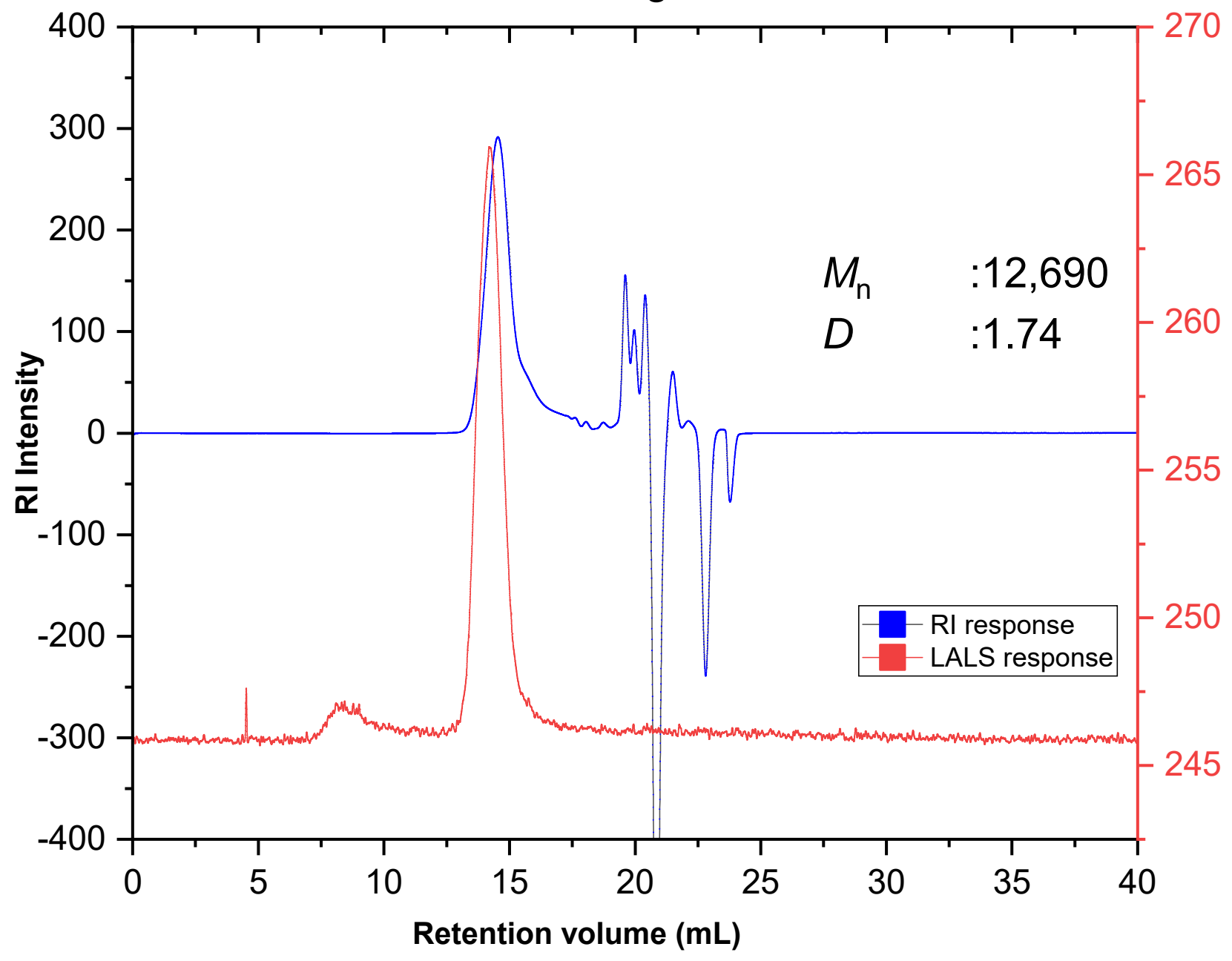

Figure S 13: RI and LALS response of polymer P1H 


\section{GPC chromatograms of P3}

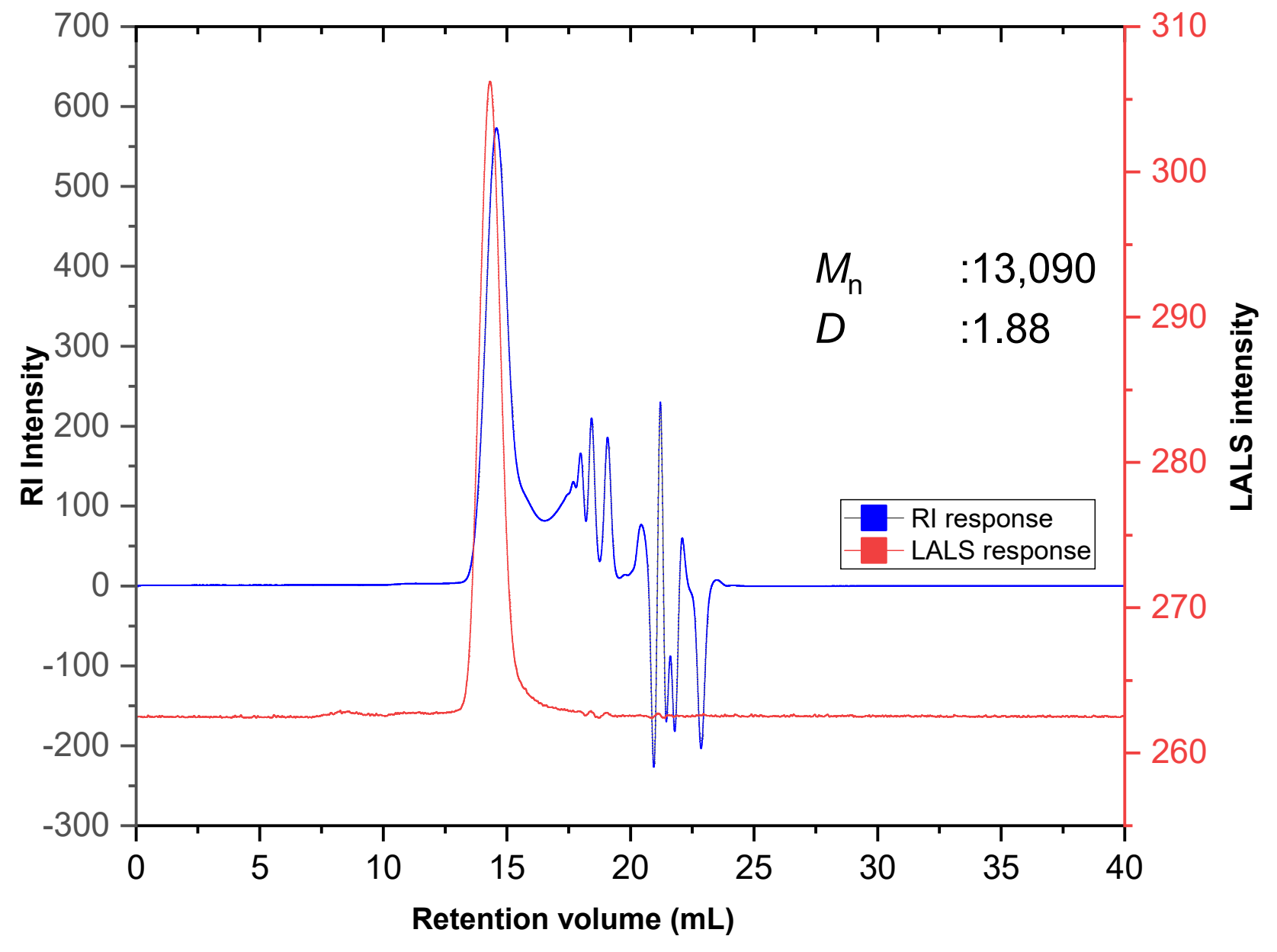

Figure S 14: RI and LALS response of polymer P3 

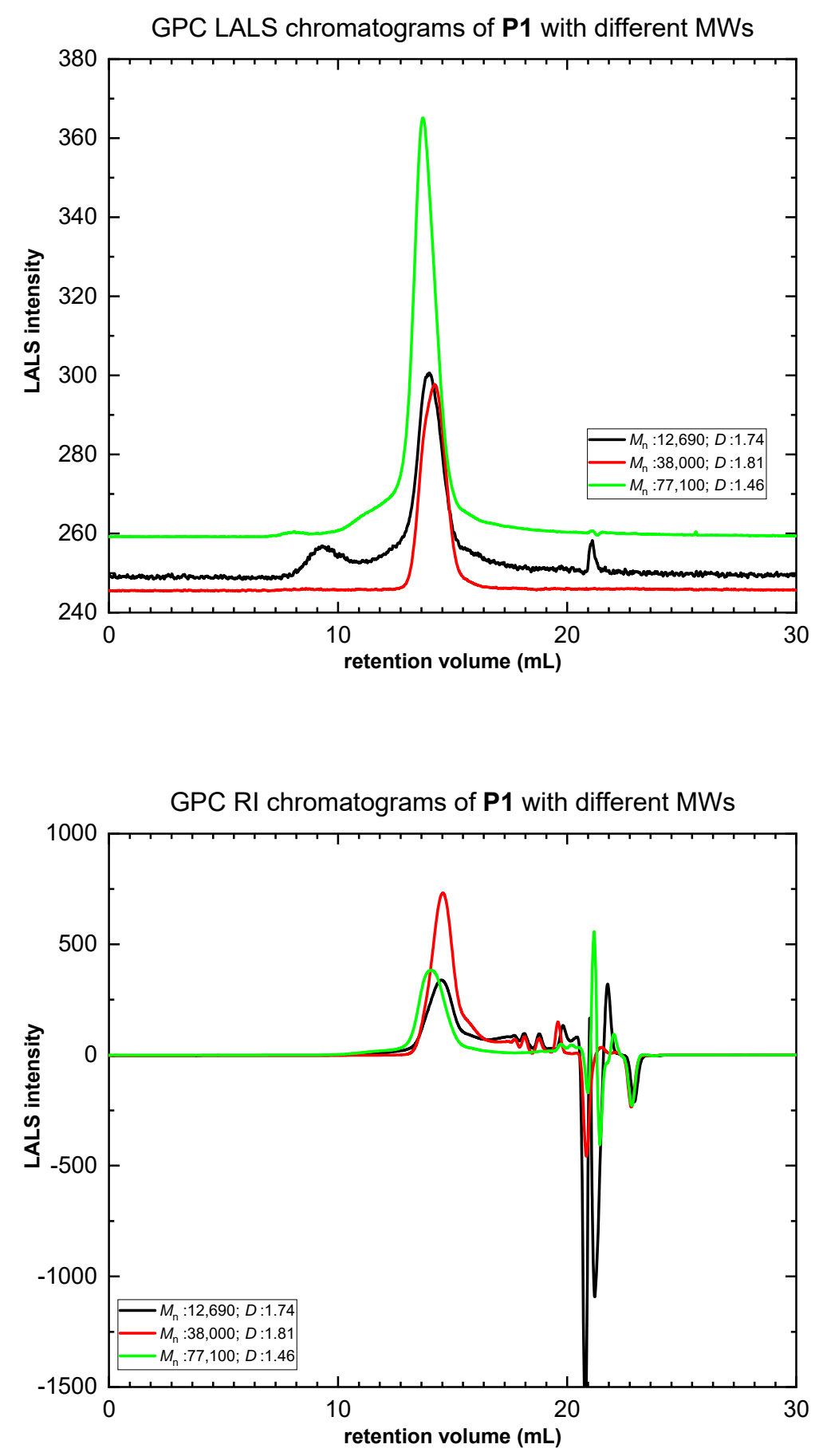

Figure S 15: GPC chromatograms of low (black), medium (red) and high (green) molecular weight $\mathbf{P 1}$ polymers. 


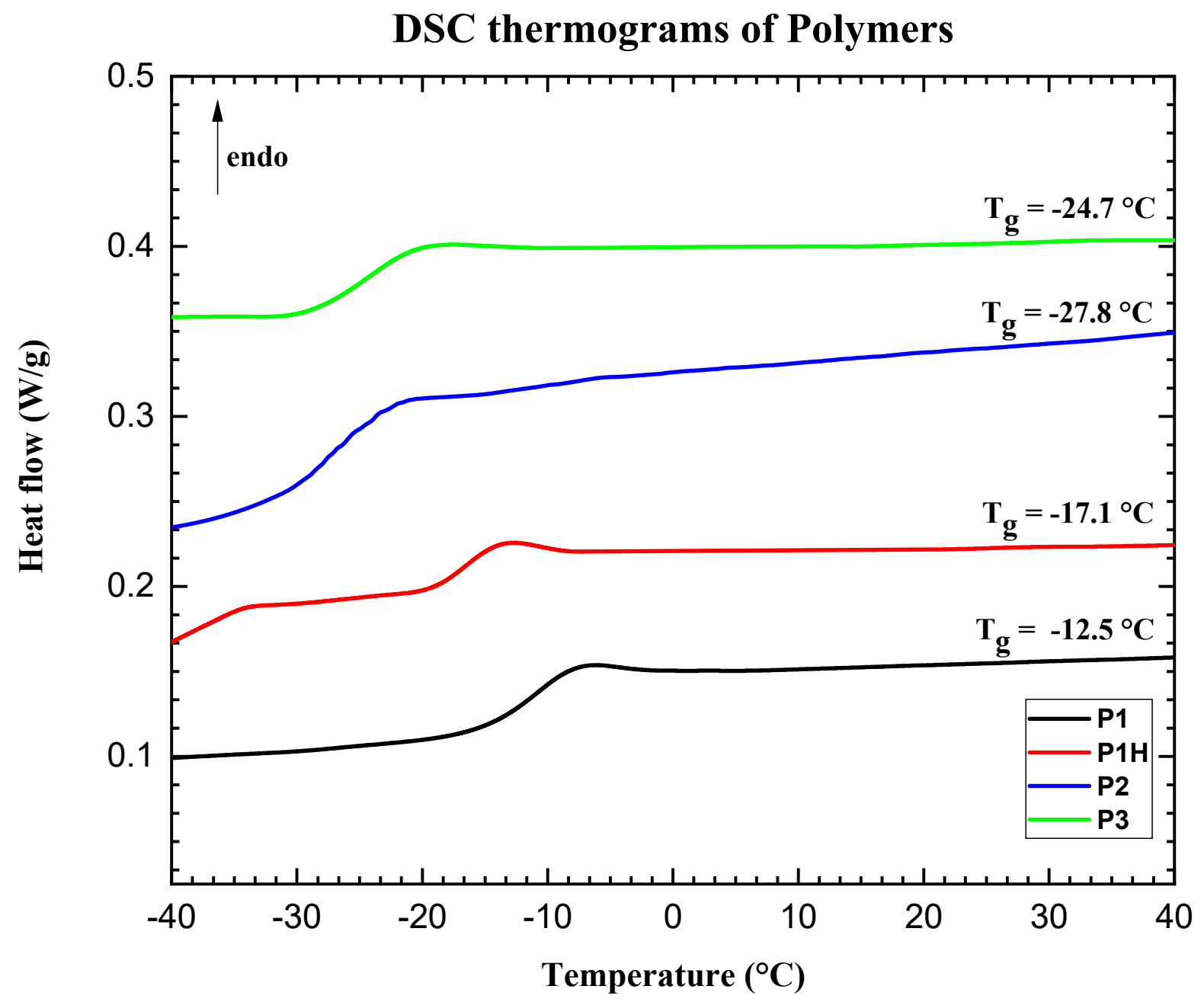

Figure S 16: DSC thermograms of P1-P3 


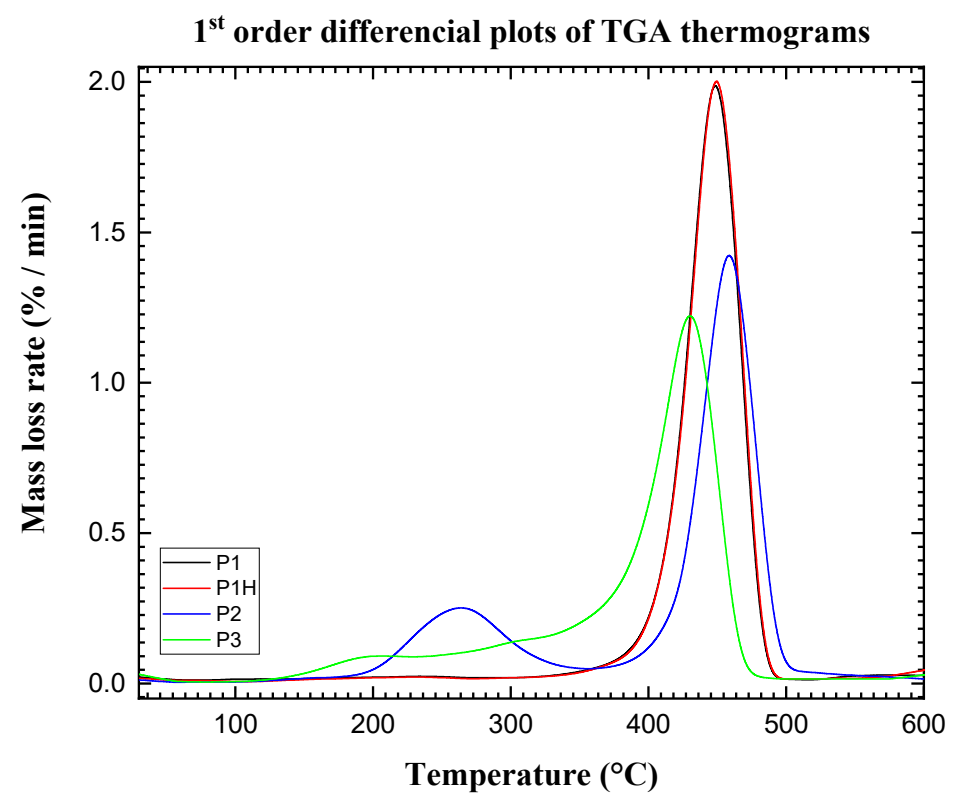

Thermogravimetric analyses of Polymers

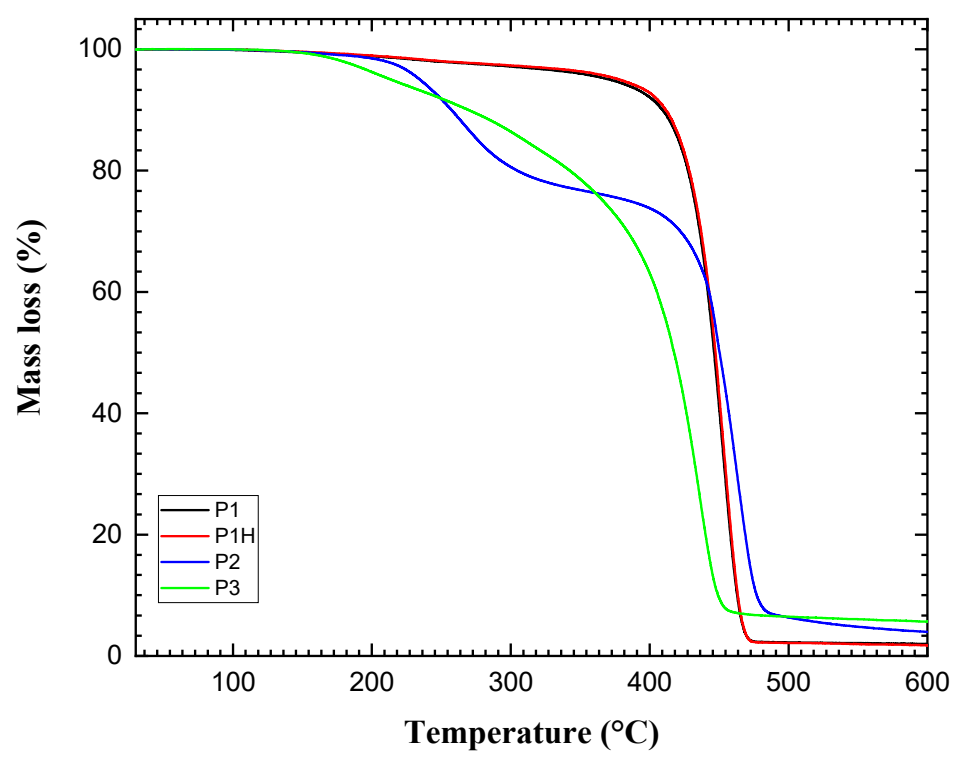

Figure S 17: Thermogravimetric (left) and 1 ${ }^{\text {st }}$-order differential TGA curves of P1-P3. 

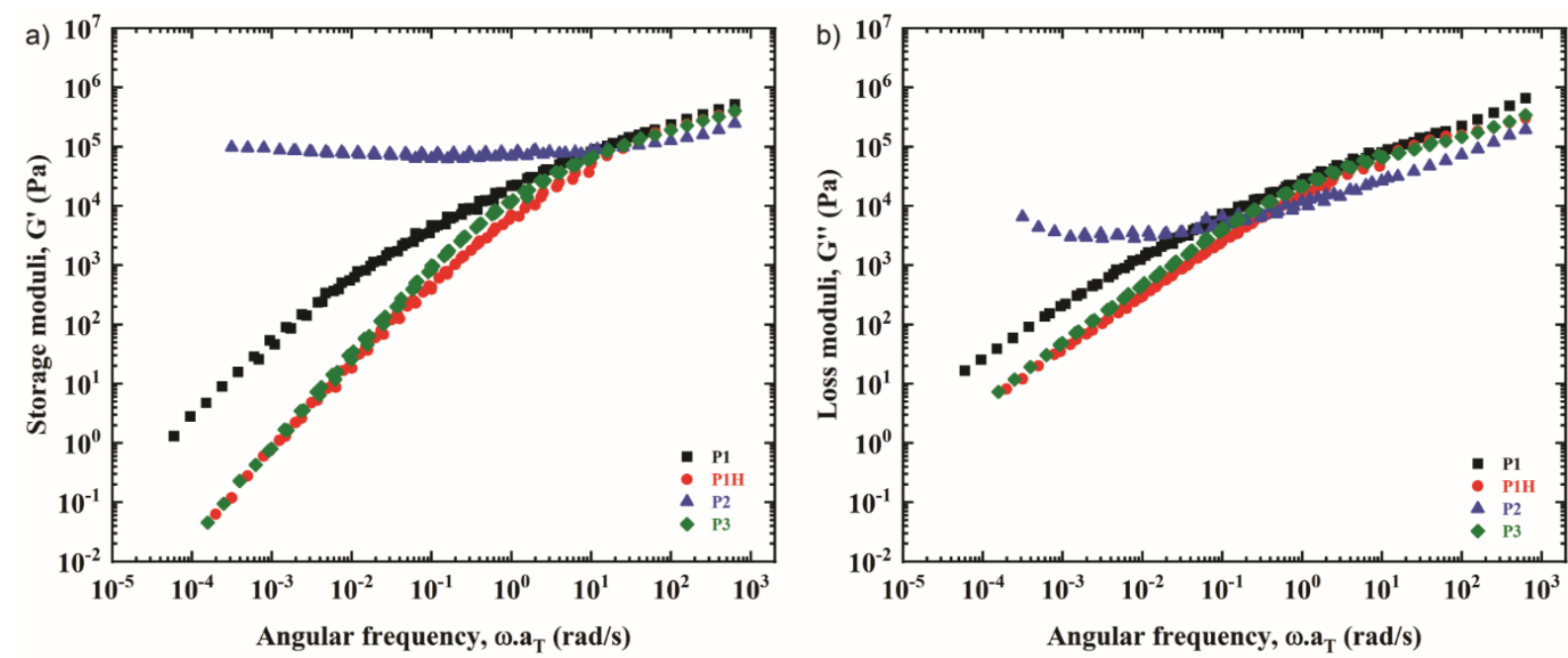

Figure S 18: Evolution of (a) storage and (b) loss moduli, G' and G" versus angular frequency for samples P1- P3 with similar molecular weights (Table 1) at the reference temperature of 30 ${ }^{\circ} \mathrm{C}$.

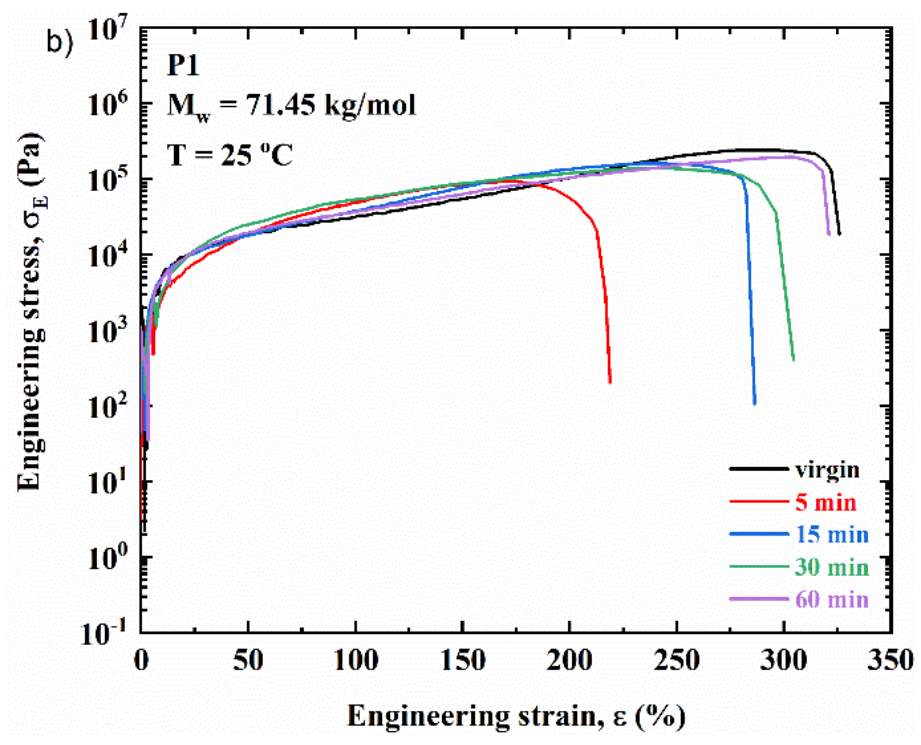

Figure S 19: Stress-strain curves for P1 $(\mathrm{Mw}=71.45 \mathrm{~kg} / \mathrm{mol})$ at various healing times ( $\mathrm{t}_{\mathrm{H}}$ from $5 \mathrm{~min}$ to $60 \mathrm{~min})$. 


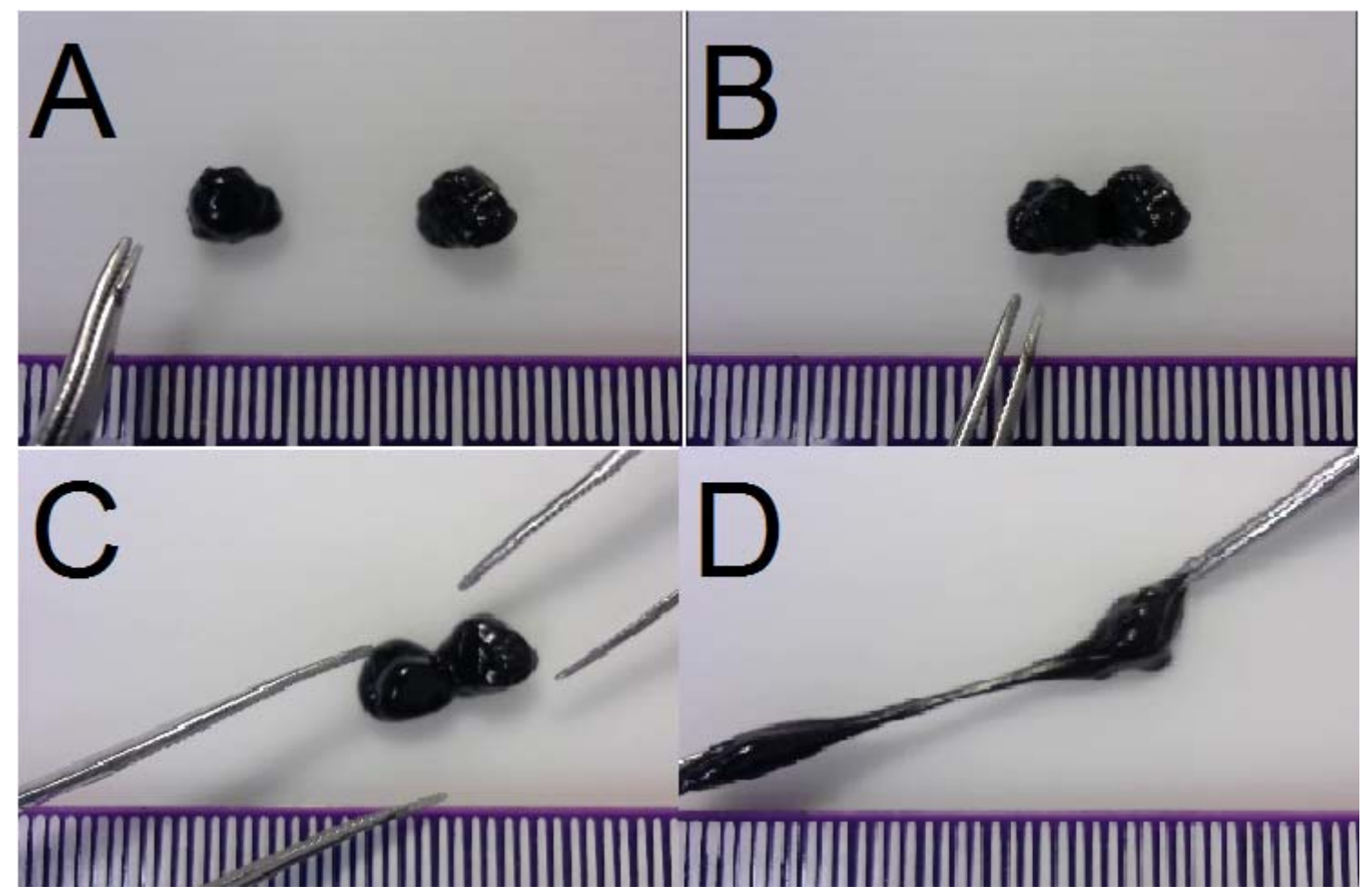

Figure S 20. Macroscopic observation of self-healing of P1 A) Dried pieces resting on PTFE B) Pieces brought into contact with minimal force C) After leaving overnight under ambient conditions $(\sim 16 \mathrm{hrs}) \mathrm{D})$ Pieces show no discrete separation when pulled apart 


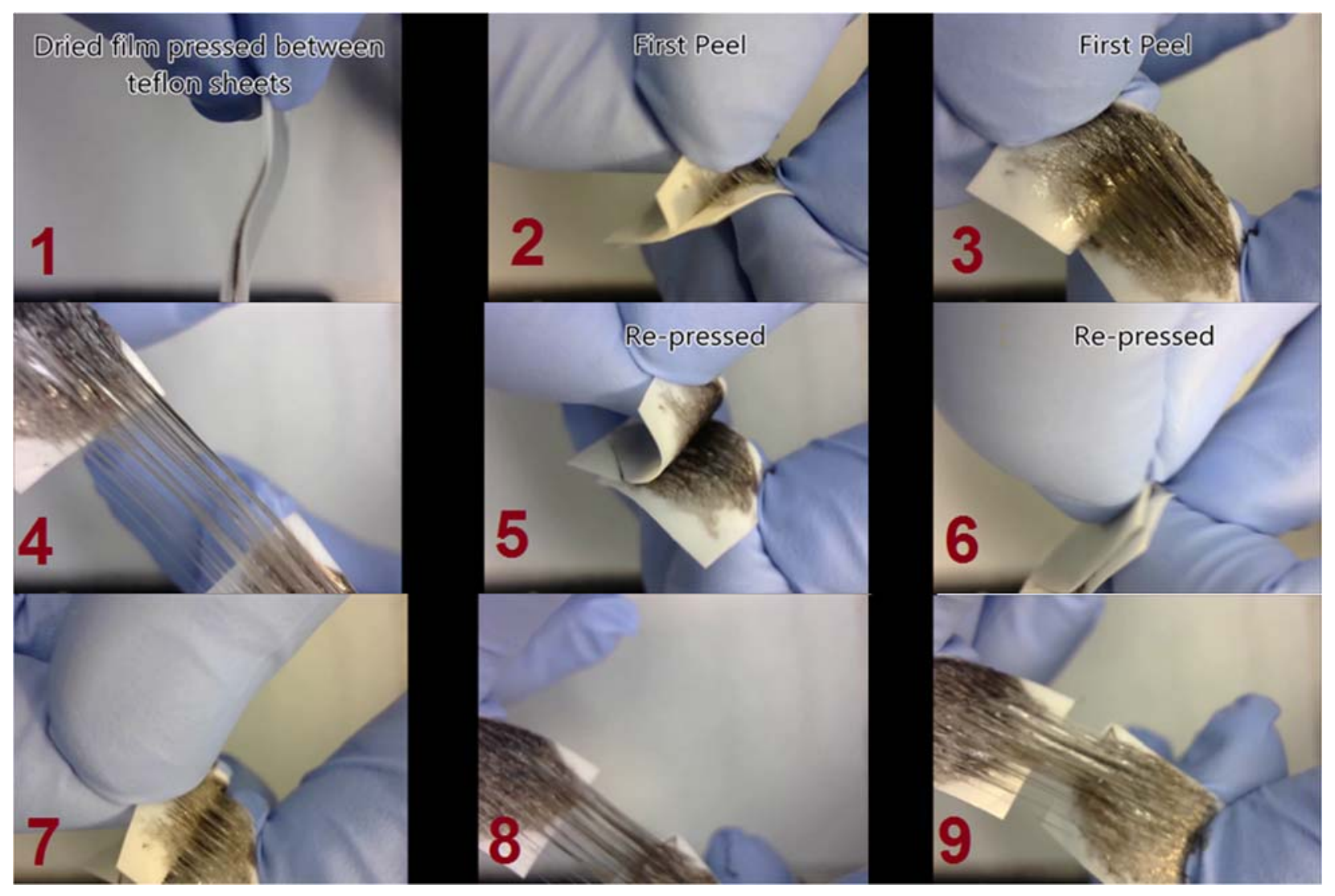

Figure S 21: Reversible adhesion between PTFE sheets using P1 


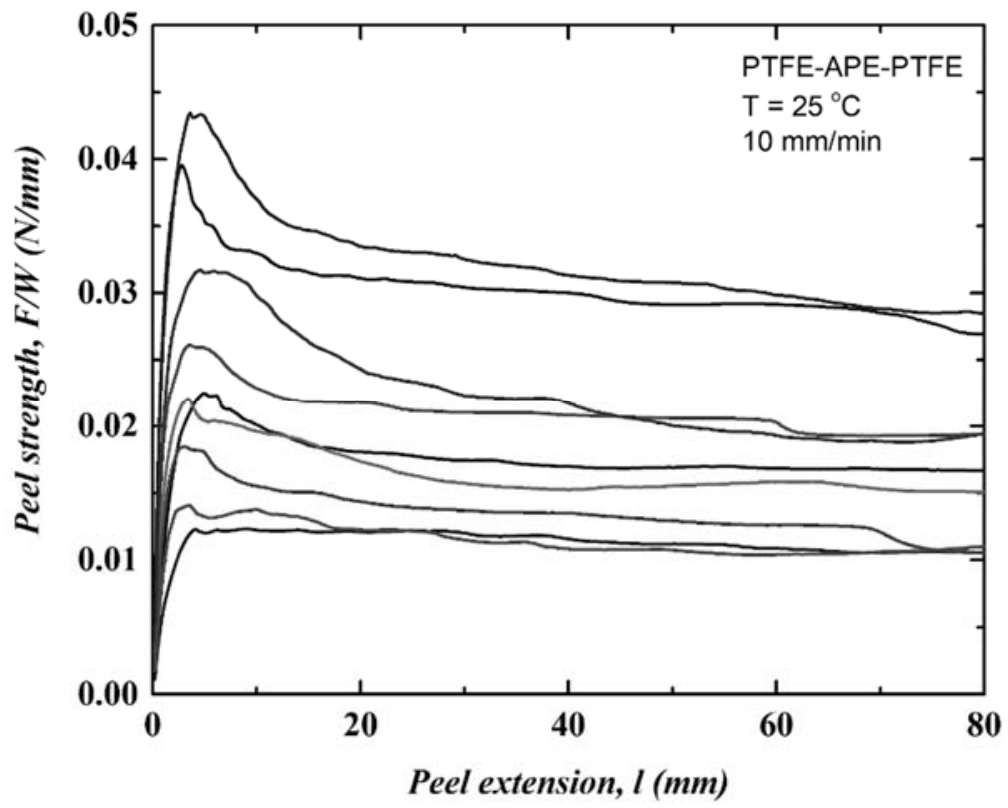

Figure S 22. Peel strength vs. peel extension for 10 PTFE-P1-PTFE samples at room temperature and peel rate of $10 \mathrm{~mm} / \mathrm{min}$

Table S1. Peel resistance results

\begin{tabular}{|c|c|c|c|c|c|c|}
\hline $\begin{array}{c}\text { samples } \\
\begin{array}{c}\text { PTFE- } \\
\text { APE- } \\
\text { PTFE }\end{array}\end{array}$ & $\begin{array}{c}\text { avg peel force } \\
\text { N }\end{array}$ & $\begin{array}{c}\text { max } \\
\text { peel } \\
\text { force }\end{array}$ & $\begin{array}{c}\text { min peel } \\
\text { force }\end{array}$ & $\begin{array}{c}\text { avg peel strength } \\
/ \mathrm{N} / \mathrm{mm}\end{array}$ & $\begin{array}{c}\text { max peel } \\
\text { strength }\end{array}$ & $\begin{array}{c}\text { min peel } \\
\text { strength }\end{array}$ \\
\hline 1 & $0.14 \pm 0.015$ & 0.18 & 0.015 & $0.017 \pm 0.0018$ & 0.022 & 0.0018 \\
\hline 2 & $0.21 \pm 0.020$ & 0.27 & 0.038 & $0.021 \pm 0.0019$ & 0.026 & 0.0036 \\
\hline 3 & $0.098 \pm 0.0096$ & 0.11 & 0.0098 & $0.011 \pm 0.0011$ & 0.012 & 0.0011 \\
\hline 4 & $0.14 \pm 0.017$ & 0.19 & 0.027 & $0.016 \pm 0.002$ & 0.022 & 0.0031 \\
\hline 5 & $0.10 \pm 0.011$ & 0.13 & 0.016 & $0.011 \pm 0.0013$ & 0.014 & 0.0018 \\
\hline 6 & $0.26 \pm 0.023$ & 0.34 & 0.047 & $0.030 \pm 0.0027$ & 0.039 & 0.0055 \\
\hline 7 & $0.12 \pm 0.018$ & 0.16 & 0.021 & $0.013 \pm 0.0019$ & 0.018 & 0.0023 \\
\hline 8 & $0.22 \pm 0.037$ & 0.32 & 0.039 & $0.022 \pm 0.0037$ & 0.032 & 0.0039 \\
\hline 9 & $0.27 \pm 0.033$ & 0.37 & 0.046 & $0.032 \pm 0.0039$ & 0.043 & 0.0054 \\
\hline all & $0.17 \pm 0.02$ & 0.23 & 0.029 & $0.019 \pm 0.0022$ & 0.026 & 0.0031 \\
\hline
\end{tabular}




\section{References}

1. Chisholm, M. H.; Huffman, J. C.; Tan, L.-S. Chloro (dimethylamido) compounds of tantalum (V): Preparations, properties, and structures of [Ta (NMe2) 3Cl2] 2, TaCl3 (NMe2) 2 (HNMe2), Ta (NMe2) 3Cl2 (HNMe2), and [TaCl2 (NMe2) 2 (HNMe2)] 2O. Inorg. Chem. 1981, 20 (6), 1859-1866.

2. $\quad$ Brandt, J. W.; Chong, E.; Schafer, L. L. Ligand Effects and Kinetic Investigations of Sterically Accessible 2-Pyridonate Tantalum Complexes for Hydroaminoalkylation. ACS Catal. 2017, 6323-6330.

3. Love, J. A.; Morgan, J. P.; Trnka, T. M.; Grubbs, R. H. A Practical and Highly Active Ruthenium-Based Catalyst that Effects the Cross Metathesis of Acrylonitrile. Angew. Chem., Int. Ed. 2002, 41 (21), 4035-4037.

4. $\quad$ Eisenberger, P.; Ayinla, R. O.; Lauzon, J. M. P.; Schafer, L. L. Tantalum-Amidate Complexes for the Hydroaminoalkylation of Secondary Amines: Enhanced Substrate Scope and Enantioselective Chiral Amine Synthesis. Angew. Chem., Int. Ed. 2009, 48 (44), 8361-8365.

5. Mango, L. A.; Lenz, R. W. Hydrogenation of unsaturated polymers with diimide. Makromol. Chem. 1973, 163 (1), 13-36.

6. Hahn, S. F. An improved method for the diimide hydrogenation of butadiene and isoprene containing polymers. J. Polym. Sci., Part A: Polym. Chem 1992, 30 (3), 397-408. 